Estudios sobre armas antiguas, arte militar y vida cultural en oriente y occidente XXXIII (2013), pp. 7-38

ISSN : 0436-029X

doi: 10.3989/gladius.2013.0001

\title{
LA PANOPLIA EN LOS VASOS DEL TOSSAL DE SANT MIQUEL (LLÍRIA). ENSAYO DE INTERPRETACIÓN ICONOGRÁFICA
}

\author{
WEAPONRY DEPICTED IN THE VASES FROM THE TOSSAL OF SANT MIQUEL (LLÍRIA). \\ STUDY OF ICONOGRAPHIC INTERPRETATION
}

POR

Susana Rosa Pérez Ferrandis*

\section{RESUMEN - ABSTRACT}

El conjunto de más de 225 vasos con decoración figurada encontrados en El Tossal de Sant Miquel (TSM) de Lliria, con una cronología que se encuadra en la segunda etapa del Ibérico Pleno, entre los siglos III a.C. a principios del II a.C, y publicados por vez primera en el Corpus Vasorum Hispanorum, ofrece una iconografía rica en elementos armamentísticos. A través de su análisis se pretende determinar si existe una panoplia edetana y si ésta varía según los llamados «Estilos I y II». (Ballester, 1935, 1954; Bonet, 1995; Aranegui et alii, 1997b; Pérez Ballester, Mata, 1998; Izquierdo, Pérez Ballester, 2005).

The set of more than 225 vases with figurative decoration found in El Tossal de Sant Miquel (TSM), Lliria, with a chronology that it is fitted in the second stage of the Middle Iberian, between IIIrd century B.C. at the beginning of the IInd B. C, and published by first time in the Corpus Vasorum Hispanorum, offers a rich iconography in arms elements. Across his analysis it is tried to determine if a edetana panoply exists and if this one changes according to so called «Styles I and II». (Ballester, 1935, 1954; Bonet, 1995; Aranegui et alii, 1997b; Pérez Ballester, Mata, 1998; Izquierdo, Perez Ballester, 2005).

\section{Palabras Clave - Keywords}

Cultura ibérica; cerámica; iconografía; armas; panoplia; Tossal de Sant Miquel.

Iberian Culture; ceramic; iconography; weapon; panoply; Tossal de Sant Miquel.

\section{INTRODUCCIÓN ${ }^{1}$}

En la elaboración de este trabajo se han recogido los estudios realizados por diversos autores especialmente Fernando Quesada Sanz, sobre el armamento ibérico del área levantina. Se han tenido en cuenta además de los vasos con decoración figurada del TSM, los ajuares encontrados en las necrópolis circundantes al territorio de Edeta así como en algunos poblados excavados de la zona, habida cuenta de que en el área edetana no se encontró ninguna necrópo-

* Departament de Prehistòria i Arqueologia, Universitat de València, supefe@alumni.uv.es.

1 El presente artículo es un resumen de nuestro trabajo de Investigación de Tercer Ciclo: "La panoplia en los vasos del Tossal de Sant Miquel (Lliria): ensayo de interpretación iconográfica" dirigido por el profesor José Pérez Ballester de la Universitat de València, a quien queremos agradecer su gran ayuda y dedicación, sin las cuales no habría sido posible su realización. 
lis (Mata, 1993). Así mismo se han valorado en la medida de lo posible, otras representaciones iconográficas, tales como algunas estelas encontradas en esta zona con iconografía armamentística, otros vasos con decoración figurada que nos han servido para compararlos con los nuestros, exvotos y esculturas hallados en ambientes mediterráneos, y en definitiva, cuanta información nos ha podido ayudar a entender y analizar el objeto de nuestra investigación.

Pero para proceder a este análisis era indispensable contar con un inventario en el que situar los vasos con los que íbamos a trabajar, y para ello aprovechamos el trabajo de análisis y ficheros realizados dentro del proyecto «La Sociedad Ibérica a través de sus cerámicas (CICYT)», dirigido por la profesora Carmen Aranegui y elaborado por los profesores Consuelo Mata Parreño y José Pérez Ballester, en el que incluimos las variaciones necesarias con el fin de cubrir la casuística específica del armamento ibérico. Después de realizar el acopio de la información existente y tras analizar el armamento representado en las cerámicas, siempre teniendo en cuenta que en ocasiones aparece incompleta, procedimos a su catalogación e inclusión en el inventario para su posterior recuento y como base para extraer las oportunas conclusiones.

\section{RESULTADOS DEL ANÁLISIS}

La elaboración del inventario nos ha permitido hacer un análisis cuyos resultados se reflejan en el cuadro 1. El número de inventario que hemos utilizado es el mismo que se utilizó para la confección del Corpus Vasorum Hispanorum. Cerámica del Cerro de San Miguel de Liria. Ballester, Fletcher, Pla, Jorda, y Alcácer, (1954).

Cuadro 1. Inventario de armas.

\begin{tabular}{|c|c|c|c|c|c|c|}
\hline ESTILO & $\begin{array}{c}\mathbf{N}^{\circ} \\
\text { INVENTARIO }\end{array}$ & $\begin{array}{c}\mathrm{N}^{\circ} \\
\text { ACCIONES }\end{array}$ & ACCION & ESCENAS & PERSONAJE & ARMAS \\
\hline I & 3 & $\begin{array}{l}3 \\
4\end{array}$ & $\begin{array}{l}\text { doma } \\
\text { doma } \\
\text { doma } \\
\text { doma } \\
\text { lucha } \\
\text { lucha } \\
\text { lucha? }\end{array}$ & $\begin{array}{c}\text { doma } \\
\text { doma } \\
\text { doma } \\
\text { doma } \\
\text { enfrentamiento } \\
\text { enfrentamiento } \\
\text { enfrentamiento }\end{array}$ & $\begin{array}{l}\text { Jinete } \\
\text { jinete } \\
\text { Infante } \\
\text { Infante } \\
\text { infante } \\
\text { infante } \\
\text { infante }\end{array}$ & $\begin{array}{c}\text { casco } \\
\text { casco } \\
\text { casco } \\
\text { casco } \\
\text { casco, falcata, caetra, jabalina } \\
\text { casco, jabalina, falcata, caetra } \\
\text { casco }\end{array}$ \\
\hline I & 24 & 1 & $\begin{array}{l}\text { lucha } \\
\text { lucha }\end{array}$ & $\begin{array}{l}\text { enfrentamiento } \\
\text { enfrentamiento }\end{array}$ & $\begin{array}{l}\text { infante } \\
\text { infante }\end{array}$ & $\begin{array}{c}\text { casco, jabalina } \\
\text { casco, jabalina, falcata }\end{array}$ \\
\hline I & 30 & 1 & caza & caza & infante & casco, jabalina, espada \\
\hline I & 32 & 1 & caza & caza & jinete & casco, espada? \\
\hline I & 114 & 1 & Indeterminable & Indeterminable & Indeterminable & caetra \\
\hline I & 122 & 1 & $\begin{array}{l}\text { lucha } \\
\text { lucha } \\
\text { lucha } \\
\text { lucha } \\
\text { lucha } \\
\text { lucha }\end{array}$ & $\begin{array}{l}\text { enfrentamiento } \\
\text { enfrentamiento } \\
\text { enfrentamiento } \\
\text { enfrentamiento } \\
\text { enfrentamiento } \\
\text { enfrentamiento }\end{array}$ & $\begin{array}{l}\text { Jinete } \\
\text { Infante } \\
\text { Infante } \\
\text { Infante } \\
\text { Infante } \\
\text { Infante }\end{array}$ & $\begin{array}{l}\text { casco, jabalina, espada, caetra } \\
\text { casco, jabalina, caetra } \\
\text { casco } \\
\text { casco, caetra, jabalina } \\
\text { casco, caetra } \\
\text { casco }\end{array}$ \\
\hline I & 125 & $\begin{array}{l}1 \\
2\end{array}$ & $\begin{array}{c}\text { Indeterminable } \\
\text { lucha }\end{array}$ & $\begin{array}{l}\text { Indeterminable } \\
\text { enfrentamiento }\end{array}$ & $\begin{array}{l}\text { infante } \\
\text { infante }\end{array}$ & $\begin{array}{l}\text { lanza, puñal } \\
\text { falcata?, caetra }\end{array}$ \\
\hline I & 144 & 1 & caza & caza & jinete & jabalina, falcata? \\
\hline
\end{tabular}




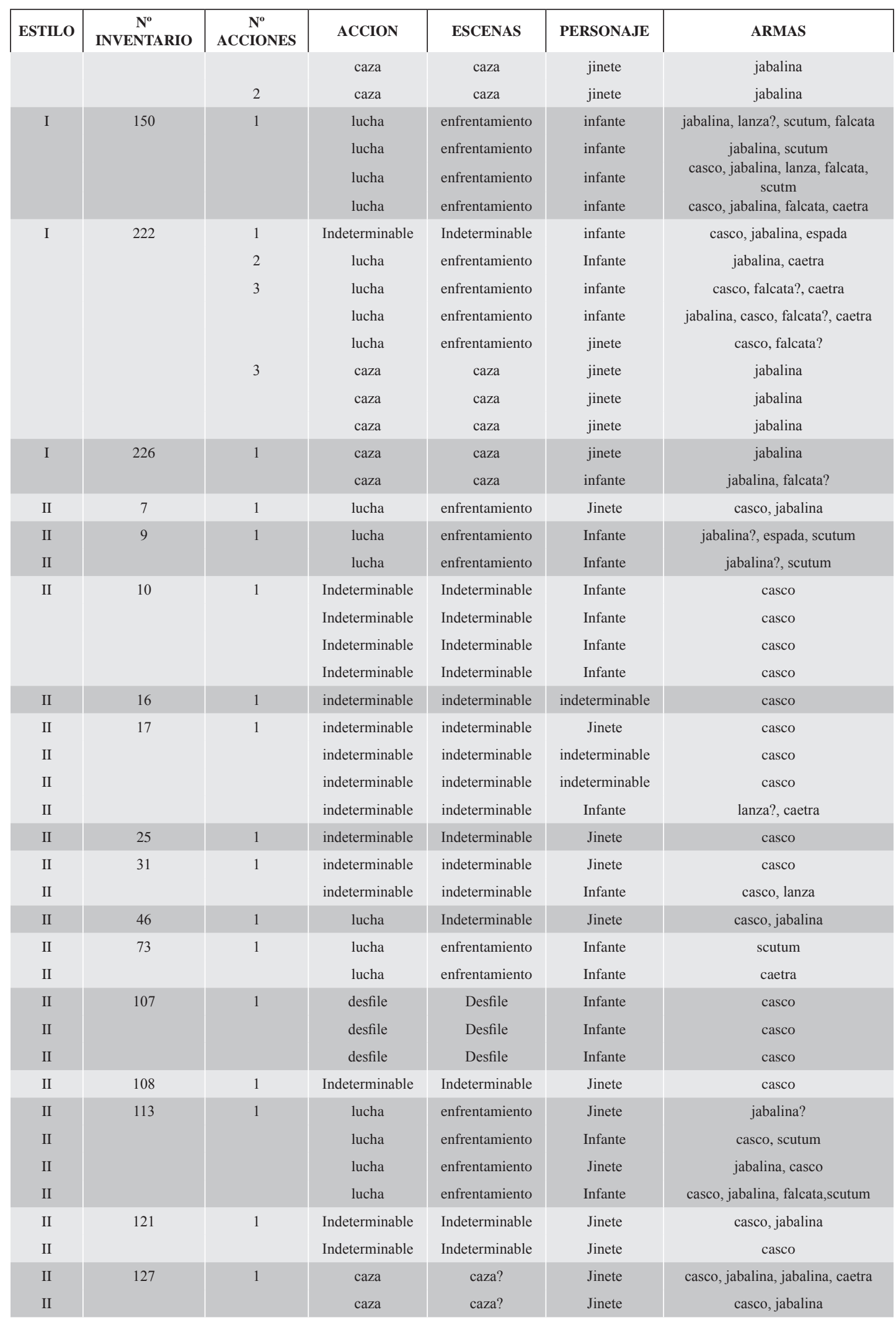




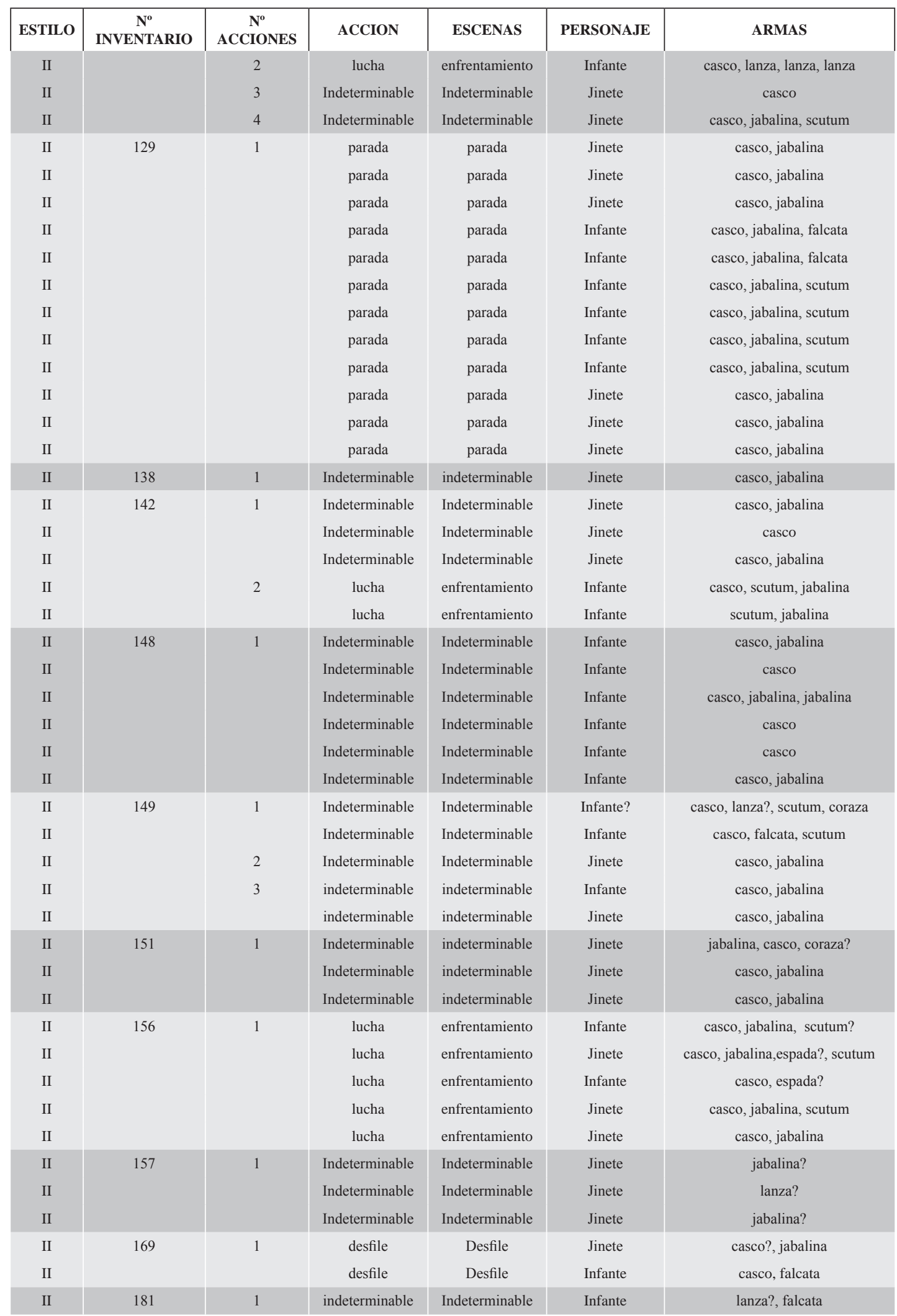


En primer lugar hemos ordenado los vasos dependiendo de la técnica con que se realizaron sus dibujos, esto es Estilo I (figuras planas o silueteadas) y Estilo II (figuras perfiladas o dibujadas) (Ballester, Fletcher, Pla, Jorda, y Alcácer, 1954; Bonet, 1995; Aranegui et alii, 1997b; Pérez Ballester y Mata, 1998; Izquierdo y Pérez Ballester, 2005).

El Estilo I se caracteriza por utilizar el relleno de tinta plana para representar figuras sencillas, con escasos detalles y en algunas ocasiones pintadas toscamente. Son escasos los motivos, vegetales que se utilizan para recrear el ambiente silvestre, enfatizar escenas o como símbolo de sustitución, y predominan las figuras humanas, en su mayoría masculinas, en escenas de enfrentamientos $(42,11 \%)$, caza $(31,58 \%)$, doma $(10,53 \%)$ o situaciones indeterminables $(15,79 \%)$, con una narración que oscila entre la presentación de una única secuencia y la muy compleja, con varias secuencias en ambientes diferentes (Pérez Ballester, 1998). Hemos observado 37 personajes que portan armas en el Estilo I entre infantes y jinetes, que participan en unos casos en acciones que suponemos pertenecen a la vida cotidiana de los habitantes del poblado, tales como doma y caza y otras que son una representación de acontecimientos lúdicos, rituales o de combate, en algunos casos desde embarcaciones.

El Estilo II, más perfeccionado que el anterior, emplea la técnica de dibujar las figuras perfiladas, con múltiples detalles, incluso rozando el barroquismo, en ocasiones con acabado irregular y otras veces con un estilo muy cuidado. En él se manifiesta el horror vacui mediante la profusión de elementos decorativos vegetales o geométricos, que rellenan de manera exagerada prácticamente todos los espacios compositivos de las escenas, en las que encontramos figuras humanas tanto masculinas como femeninas. Los 76 personajes que portan armas en los vasos atribuidos a este estilo (ver cuadro 4) participan en enfrentamientos $(26,67 \%)$, desfiles y parada (10\%), y una (o dos) de caza, en escenas que desarrollan narraciones principalmente con una única secuencia, apareciendo en sólo una ocasión en una narración compleja (Pérez Ballester, 1998).

Dentro de cada una de estas escenas de ambos estilos hemos descrito diferentes tipos de acciones: lucha, marcha, parada, remo. Así mismo hemos realizado una distinción entre los distintos tipos de personajes: infante, jinete, remero, domador, y por último, las armas que porta cada uno de los personajes estudiados (falcata, espada, puñal, lanza, jabalina, caetra, scutum, casco, coraza, grebas).

Los vasos en los que se encuentran estas representaciones no presentan una diferenciación tipológica diferenciada según su pertenencia a un estilo u otro. Tan sólo podemos decir que en el Estilo I existe un pequeño predominio de vasos con utilidad de almacenaje y rituales (lebes, tinajas, tinajillas y 1 sólo cálato) y en el Estilo II hay una mayor variedad de usos (lebes, tinajas, tinajillas, cálatos y enócoes o jarras).

EstiLo I

Cuadro 2. Tipología de escenas, repetición y número de personajes en el Estilo I.

\begin{tabular}{|l|c|c|}
\cline { 2 - 3 } \multicolumn{1}{c|}{} & $\mathrm{N}^{\circ}$ ESCENAS & $\mathrm{N}^{\circ}$ PERSONAJES \\
\hline ENFRENTAMIENTO & 8 & 20 \\
\hline CAZA & 6 & 10 \\
\hline DOMA & 2 & 4 \\
\hline INDETERMINABLE & 3 & 3 \\
\hline TOTAL & $\mathbf{1 9}$ & $\mathbf{3 7}$ \\
\hline
\end{tabular}


Comenzamos con los resultados que nos ofrecen los 11 vasos correspondientes al Estilo I con presencia de personajes armados. En ellos encontramos 19 escenas: ocho de enfrentamiento con 20 personajes ( 13 completos), seis de caza con 10 personajes ( 5 completos), dos de doma con 4 personajes ( 4 completos) y tres indeterminadas con 3 personajes ( 2 completos).

\section{Las armas y su representación en el Estilo I}

A la hora de interpretar lo que los diferentes artistas quisieron plasmar cuando dibujaron las armas que estamos estudiando, debemos tener siempre presente las convenciones que utilizaron para reflejar su representación, ya que en muchas ocasiones debieron adaptar sus imágenes a la forma del vaso en el que estaban trabajando; por ello, a veces su interpretación no es absolutamente fiable; o que por limitaciones técnicas o de representación el arma se reduce a un simple trazo. Esto es especialmente notorio en el Estilo I. (Ver cuadro 3)

Cuadro 3. Asociaciones de armas en el Estilo I

\begin{tabular}{|c|c|c|c|}
\hline ESCENA & No INVENTARIO & PERSONAJE & ARMAS \\
\hline \multirow[t]{14}{*}{ ENFRENTAMIENTO } & 3 & infante & casco, falcata, caetra, jabalina \\
\hline & 3 & infante & casco, falcata, caetra, jabalina \\
\hline & 122 & infante & casco, espada caetra, jabalina \\
\hline & 122 & infante & casco, caetra, jabalina \\
\hline & 122 & infante & casco \\
\hline & 122 & infante & casco, caetra, jabalina \\
\hline & 122 & infante & casco, caetra \\
\hline & 122 & infante & casco \\
\hline & 125 & infante & casco, falcata, scutum, jabalina, lanza \\
\hline & 150 & infante & casco, falcata, caetra, jabalina \\
\hline & 222 & infante & caetra, jabalina \\
\hline & 222 & infante & casco, falcata?, caetra \\
\hline & 222 & infante & casco, falcata?, caetra, jabalina \\
\hline & 222 & jinete & casco, falcata? \\
\hline \multirow[t]{5}{*}{ CAZA } & 30 & infante & casco, espada, jabalina \\
\hline & 144 & jinete & jabalina \\
\hline & 222 & jinete & jabalina \\
\hline & 222 & jinete & jabalina \\
\hline & 226 & jinete & jabalina \\
\hline \multirow[t]{4}{*}{ DOMA } & 3 & infante & casco \\
\hline & 3 & infante & casco \\
\hline & 3 & jinete & casco \\
\hline & 3 & jinete & casco \\
\hline \multirow[t]{2}{*}{ INDETERMINABLE } & 125 & infante & lanza, puñal \\
\hline & 222 & infante & casco, espada, jabalina \\
\hline
\end{tabular}




\section{a) Armas ofensivas:}

- Falcata representada de forma imprecisa, sin poderse distinguir detalles tipológicos: un grueso trazo que pretende mostrar su hoja no recta, en manos de infantes en mayor proporción que en jinetes.

- Espada: las diferenciamos de las anteriores porque se dibujan con un trazo de filo igualado que representa una hoja recta. Quesada propone una espada de antenas atrofiada en el vaso $n^{\circ} 122$, aunque también podría tratarse de una vaina vacía (Quesada, 1997:240).

- Puñal: documentamos un único puñal desenvainado de forma triangular y antenas atrofiadas (vaso $n^{\circ} 125$ ) en un personaje que además porta una lanza (Quesada, 1997: 296).

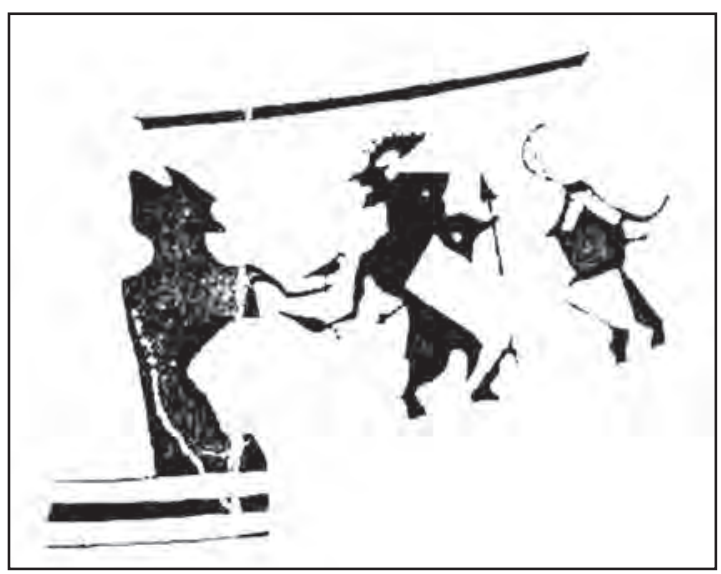

Figura 1. Vaso 125 Archivo Dpto. Prehistoria y Arqueología (UVEG).

- Armas de astil: al igual que en el Estilo II, es complicado distinguir entre los diferentes tipos de armas de astil que observamos en los dibujos. De acuerdo con Quesada hemos establecido la denominación de lanza al trazo lineal terminado en punta que se presenta estante y asida, mientras que jabalina será aquel trazo también terminado en punta en actitud de ser arrojada, o bien en el aire indicando que ha sido lanzada, o finalmente clavada en un objetivo. Cuando se dibuja con amentum es con seguridad una jabalina. En el término jabalina hemos incluido las armas de astil soliferrea y pila, armas arrojadizas que encontramos depositadas en las tumbas de las necrópolis estudiadas, aunque a la vista de los dibujos es imposible distinguir unas de otras.

\section{b) Armas defensivas:}

- Caetra: escudo cóncavo o convexo que en ocasiones aparece como radiografiado mostrando la mano asiendo unas supuestas manillas, de perfil en la mayoría de los casos, con líneas perpendiculares que se han interpretado como el pelo no curtido de una piel que se empleaba para fabricarlos (Quesada, 1997: 521). 


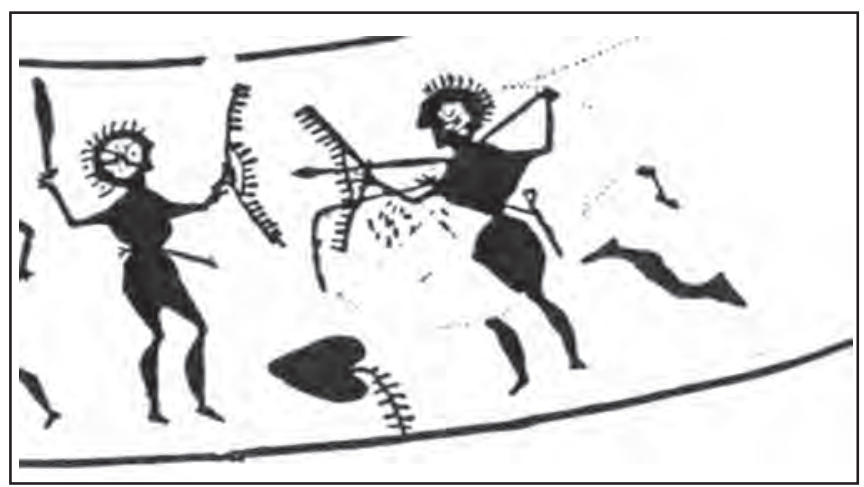

Figura 2. Vaso 3 Archivo Dpto. Prehistoria y Arqueología (UVEG).

- Scutum: lo encontramos solamente en una escena de enfrentamiento (vaso $\mathrm{n}^{\mathrm{o}} 150$ ). De forma rectangular con spina central, en dos ocasiones aparece asido por la misma mano que sujeta una jabalina, en una casi imposible posición.

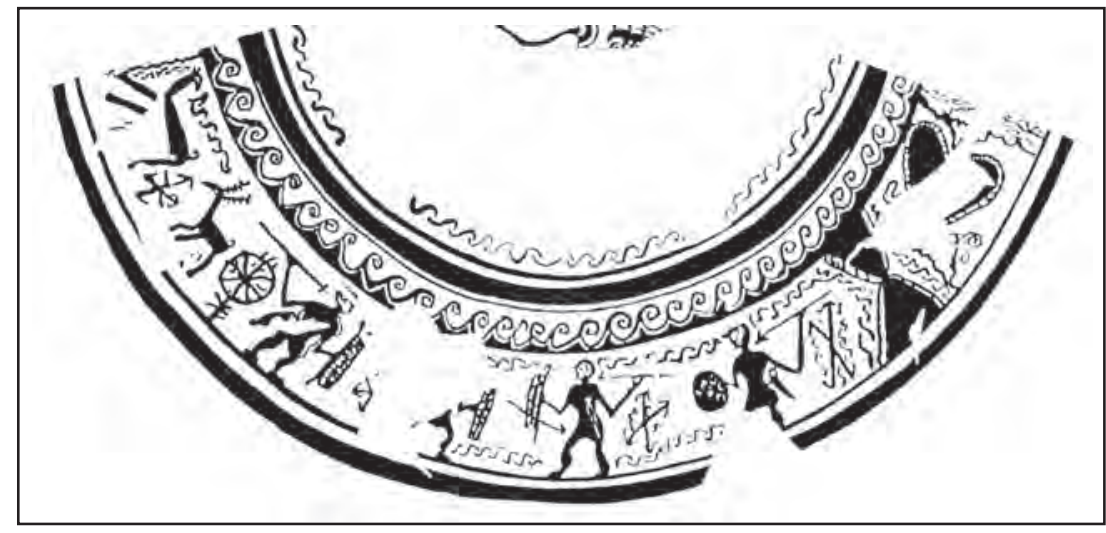

Figura 3. Vaso 150 (Archivo Dpto. Prehistoria y Arqueología (UVEG).

- Casco: se repite en casi todas las escenas, si admitimos como tal la presencia de pequeños segmentos o trazos que parten del cráneo de los personajes, aunque debemos tener precauciones a la hora de afirmar con rotundidad que se trata en realidad de estos elementos defensivos. En nuestro estudio los hemos aceptado como cascos pero planteamos el interrogante de que en realidad sea la representación ideal del cabello del personaje, puesto que difícilmente un domador o un cazador, en su actividad diaria, utiliza un casco para realizar estas tareas.

\section{Escenas y acciones en el Estilo I}

Hemos encontrado cuatro tipos de escenas representadas en este estilo, en las que participan uno o más personajes que pasamos a describir a continuación: 


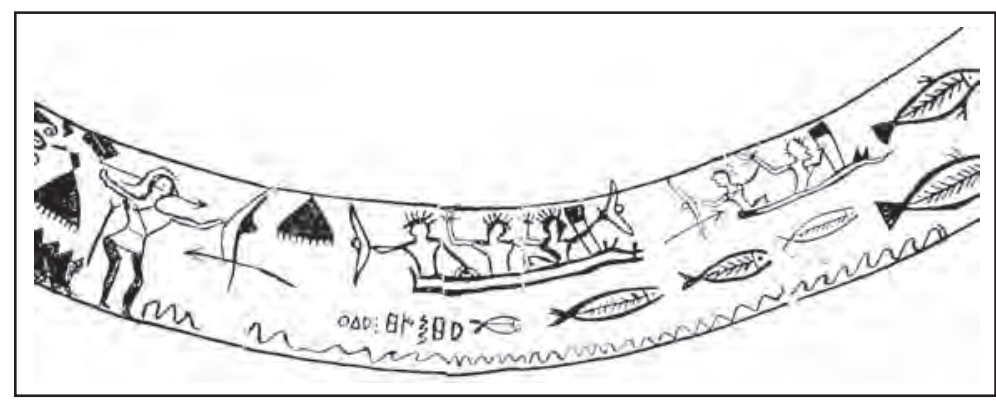

Figura 4. Vaso 122 Archivo Dpto. Prehistoria y Arqueología (UVEG).

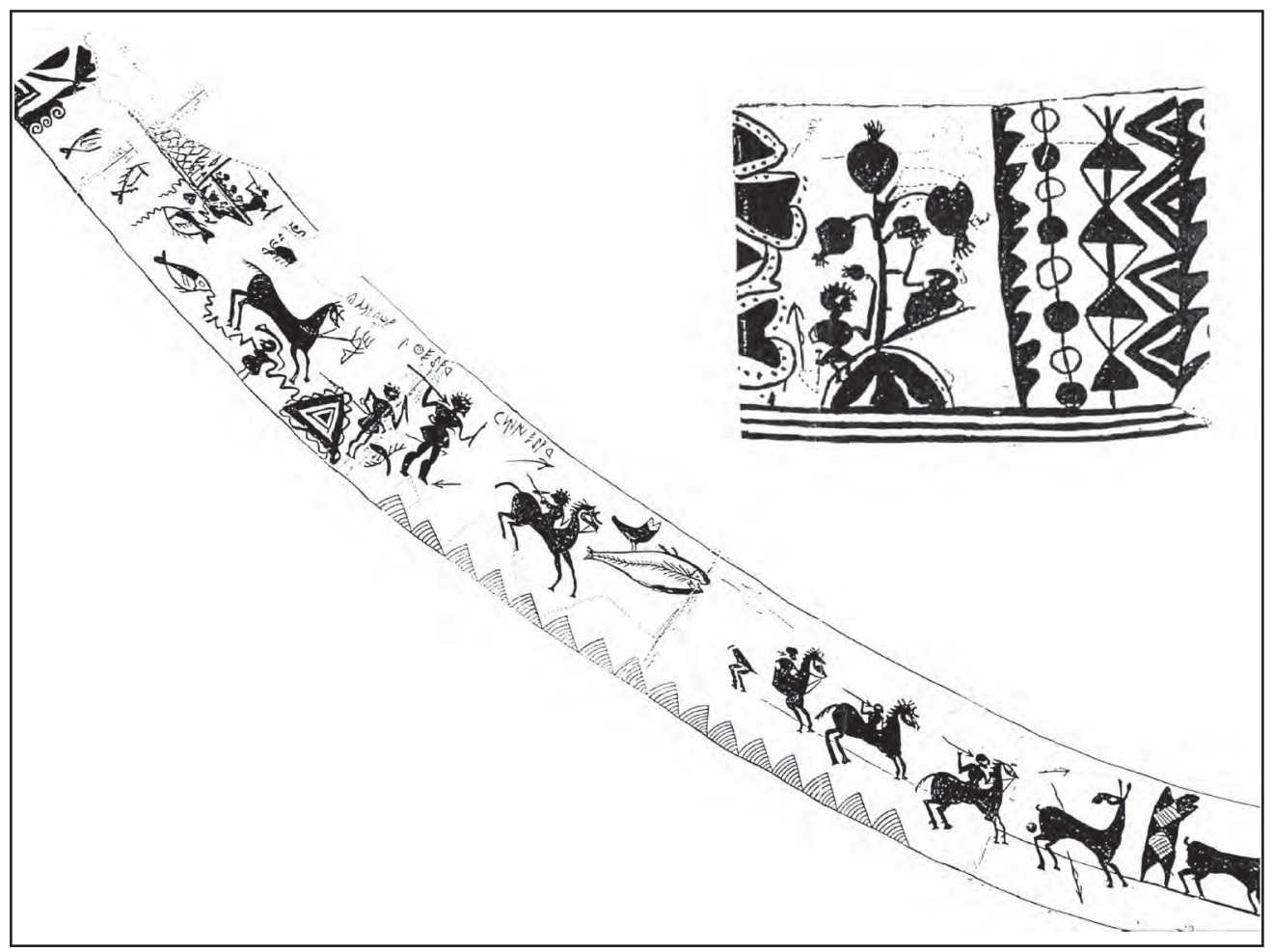

Figura 5. Vaso 222 Archivo Dpto. Prehistoria y Arqueología (UVEG).

- Enfrentamientos: Cuando los personajes luchan o se enfrentan claramente entre sí. En algunas escenas incompletas hemos encontrado un personaje que aparece herido o alcanzado por jabalinas, por lo que intuimos que se trataría de un enfrentamiento. También incluimos en esta categoría a los personajes embarcados (vaso $\mathrm{n}^{\circ} 122$ y n $^{\circ}$ 222) porque su principal papel en la escena es el estar involucrados en un enfrentamiento, aunque sea desde el interior de una embarcación.

- Caza: representación con uno o más personajes que atacan o persiguen a uno o más animales.

- Doma: acción en la que uno o más personajes evolucionan conjuntamente amaestrando o jugando aparentemente con un animal (caballo, toro). 
- Indeterminable: personajes armados cuya relación no es clara por estar muy incompleto o la acción poco definida.

Cuadro 4. número de infantes y jinetes representados en las diferentes escenas del Estilo I.

\begin{tabular}{|l|c|c|c|}
\hline \multicolumn{1}{|c|}{ ESCENA } & $\mathbf{N}^{\mathbf{0}}$ INFANTES & $\mathbf{N}^{\mathbf{0}}$ JINETES & TOTAL \\
\hline ENFRENTAMIENTO & 18 & 2 & 20 \\
\hline CAZA & 2 & 8 & 10 \\
\hline DOMA & 2 & 2 & 4 \\
\hline INDETERMINABLES & 1 & 2 & 3 \\
\hline TOTAL & 23 & 14 & 37 \\
\hline
\end{tabular}

Comprobamos que en el Estilo I predominan las escenas de enfrentamientos. Respecto al tipo de personaje representado, observamos que 24 son infantes $(64,86 \%), 12$ jinetes $(32,43 \%)$, y 3 indeterminables.

\section{La panoplia representada en el Estilo I}

Hemos analizado las asociaciones de armas que aparecen en este grupo, referidas a los personajes cuyas figuras están completas, diferenciando entre la panoplia de infantes y jinetes. Los personajes indeterminables por estar incompletos o aquellos en los que se ha perdido parte de su trazado, los utilizamos para completar la información que nos dan los primeros.

Por la variedad de asociaciones de armas que observamos en los diversos grupos de escenas, especialmente en las de enfrentamiento, resulta muy difícil establecer una panoplia tipo de guerrero propia dentro del Estilo I. Sin embargo, en cada tipo de escena hemos encontrado una asociación predominante que exponemos a continuación:

1. Escenas de enfrentamiento:

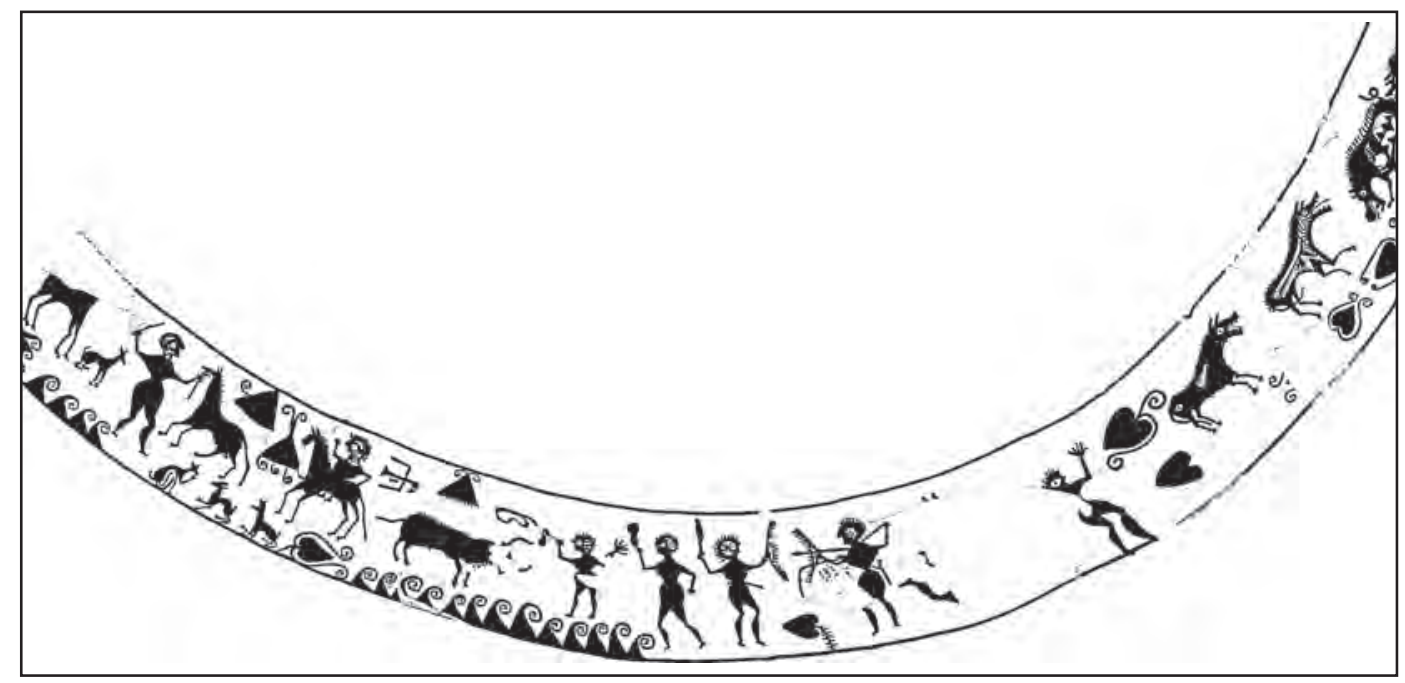

Figura 6. Vaso 3 Archivo Dpto. Prehistoria y Arqueología (UVEG). 
La panoplia predominante de los infantes es la formada por (casco), falcata, caetra y jabalina ( 3 veces +1 con falcata dudosa). Esta asociación se corresponde con la panoplia típica de los s. IV-III a.C. como hemos visto en la necrópolis de El Cigarralejo o bien es propia del periodo posterior (finales s. III a.C. principios s. II a.C.) aunque sólo en la tumba de un guerrero poderoso o líder como se constata en la necrópolis de Coimbra del Barranco Ancho (García Cano, 1997)². Observamos la escasa presencia de doble arma arrojadiza, más propia del periodo correspondiente a los s. IV-III a.C., que indica la pertenencia de su portador a un grupo de más alcurnia. En el Estilo I sólo lo hemos encontrado en dos ocasiones, ambas en una escena de enfrentamiento (vaso $\mathrm{n}^{\circ} 150$ ) y utilizadas con la misma mano con la que se sostiene un scutum. En cuanto a los jinetes, uno de ellos parece que blande una falcata y porta un casco. Sin embargo el jinete desmontado del vaso $\mathrm{n}^{\circ} 122$ luce una panoplia completa compuesta por casco, espada, caetra y jabalina. (Pérez Ballester, 1998:238).

\section{Escenas de caza.}

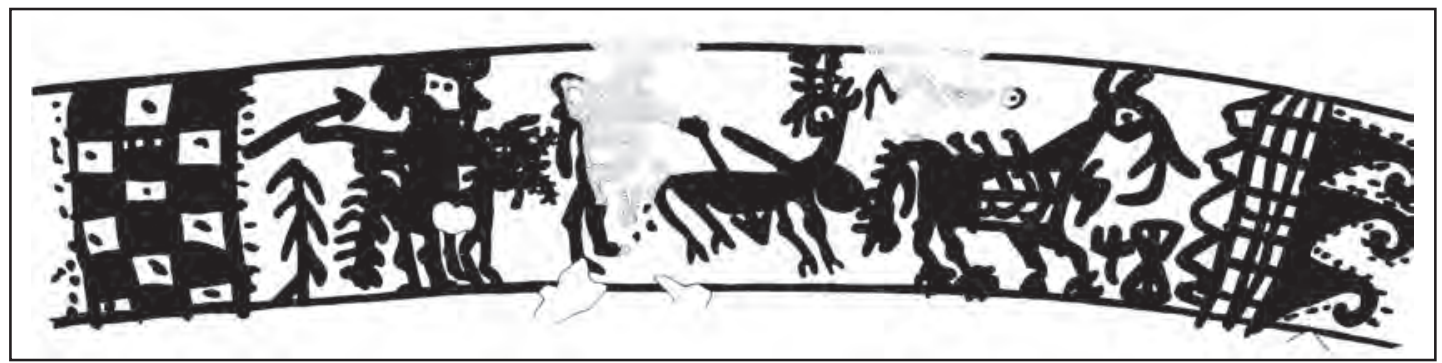

Figura 7. Vaso 226 Archivo Dpto. Prehistoria y Arqueología (UVEG).

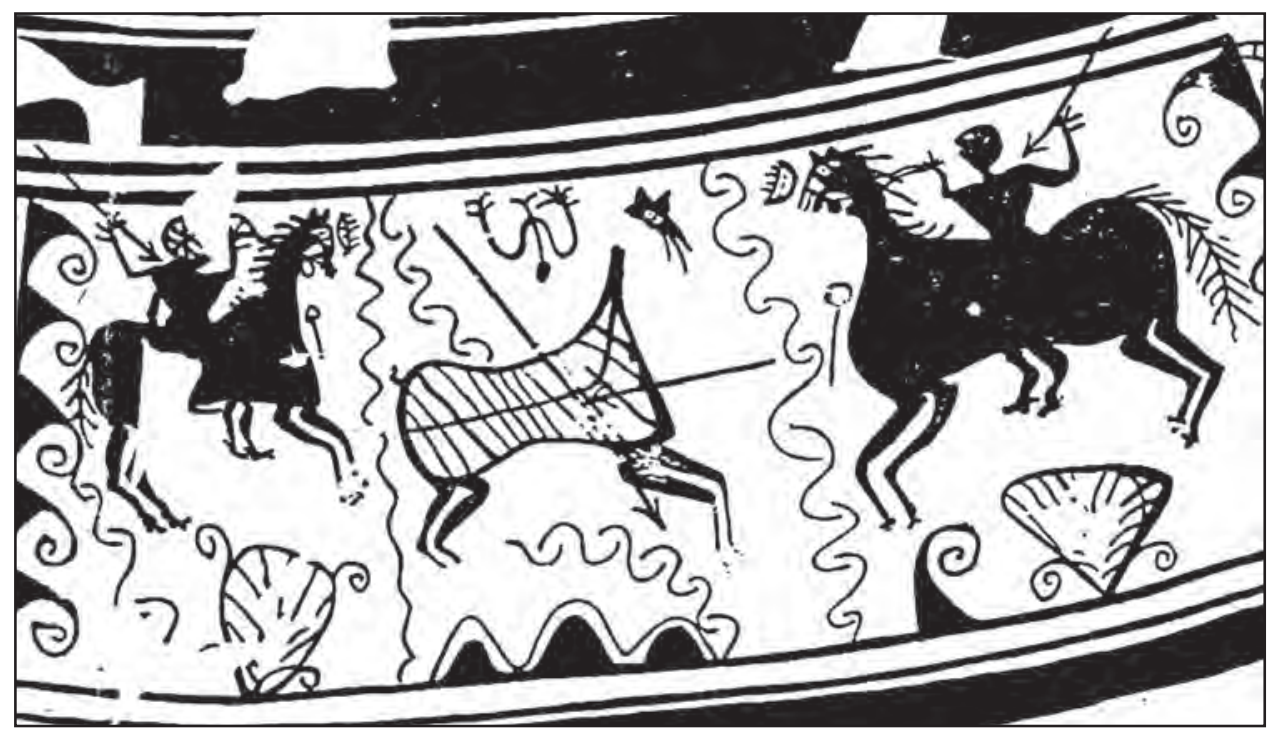

Figura 8. Vaso 144 Archivo Dpto. Prehistoria y Arqueología (UVEG).

2 Tumba $\mathrm{n}^{\mathrm{o}} 55$ correspondiente a finales del s. III a.C. en la que se encontraron falcata, soliferreum, dos puntas de lanza, un regatón, y una manilla de escudo. 
Aquí la asociación de armas es mucho más sencilla: una sola jabalina como arma ( 8 jinetes). El infante del vaso $\mathrm{n}^{\mathrm{o}} 30$ presenta una panoplia más completa (casco, jabalina y espada) pero aparece fragmentada y puede interpretarse como un personaje que se enfrenta a un monstruo o animal mítico (Kurtz, 1993: 243).

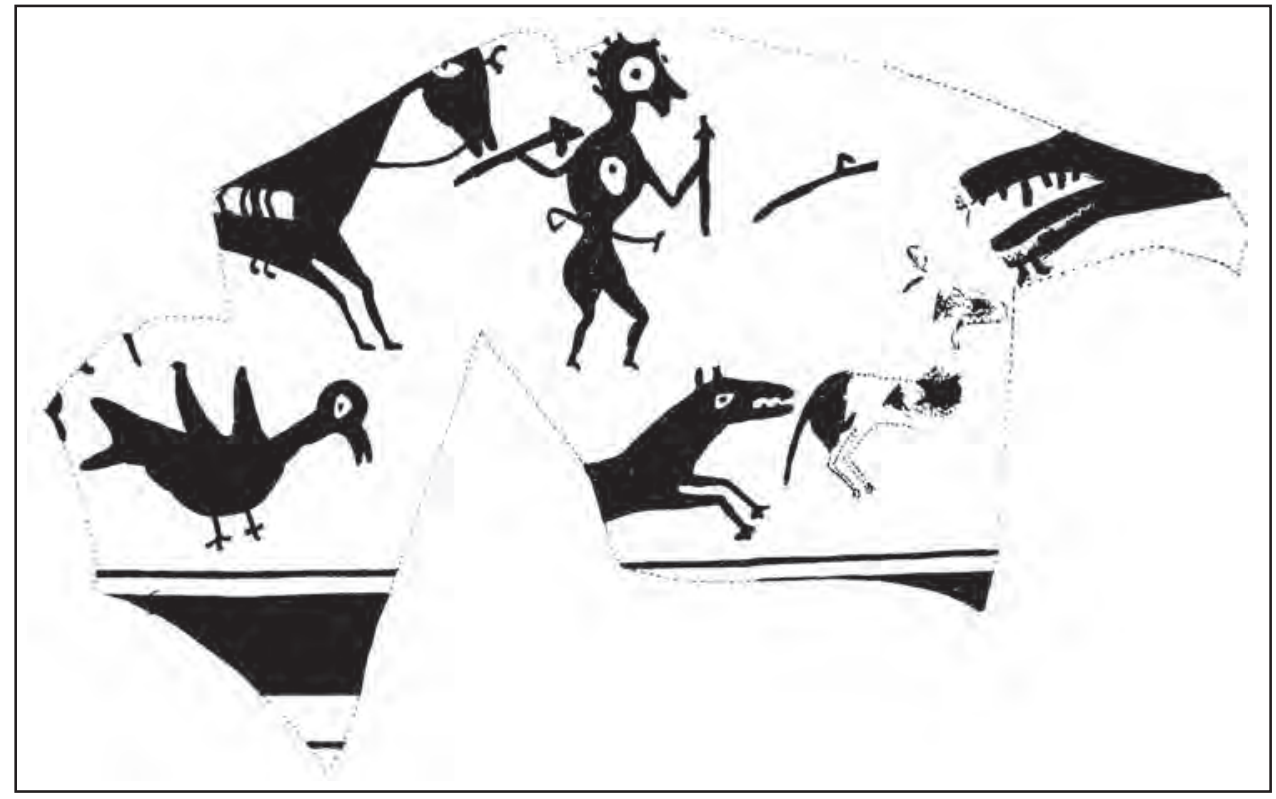

Figura 9. Vaso 30 Archivo Dpto. Prehistoria y Arqueología (UVEG).

3. Escena de doma.

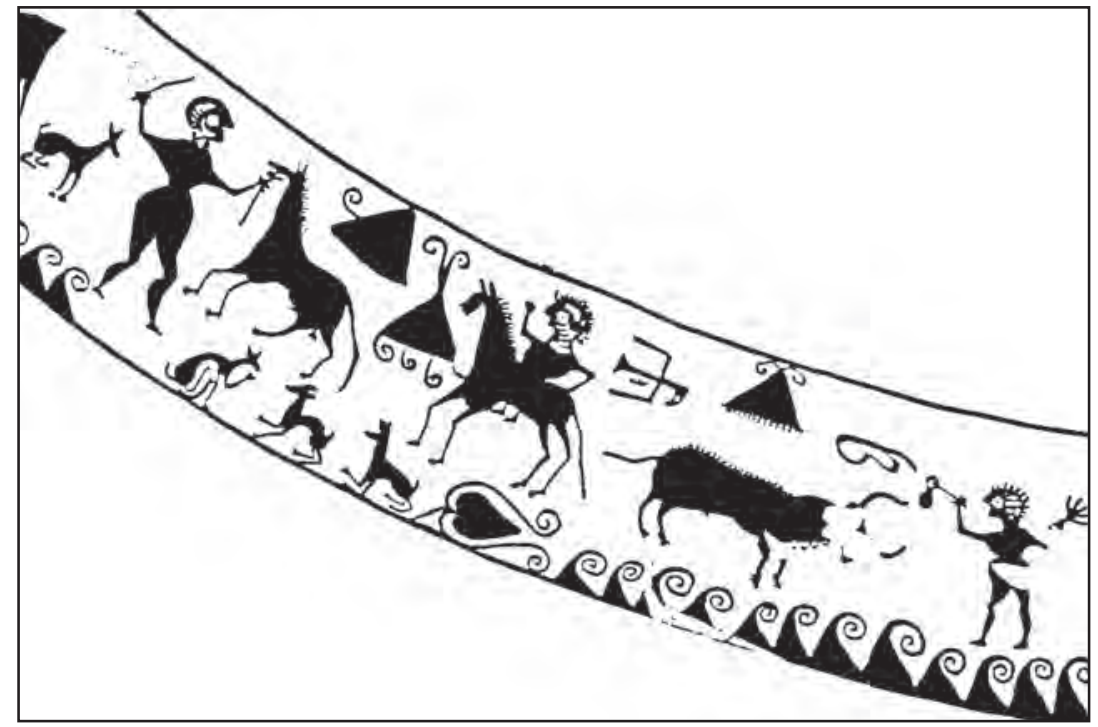

Figura 10. Vaso 3 (Archivo Dpto. Prehistoria y Arqueología (UVEG). 
En la única escena, infantes y jinetes no portan armas, sólo presentan una especie de casco o casquete, o bien tal casco no existe. No compartimos el criterio de Maestro (1989) cuando afirma que el punteo semicircular que aparece en las cabezas de las figuras de los personajes del TSM son cascos.

\section{Escenas indeterminables}

Hemos incluido dos infantes completos en este grupo, ambos peculiares y diferentes del resto, pero relevantes por su significado. El personaje del vaso $\mathrm{n}^{\mathrm{o}} 125$ es el único dentro de este grupo que porta un puñal desenvainado con la vaina al cinto y en la otra mano blande una lanza. Se le ha atribuido un carácter ritual (Aranegui et alii, 1997a:97). El del vaso no 222 se encuentra en una escena de compleja interpretación; creemos que es un infante que se encarama a un árbol con una jabalina en la que se observa claramente el amentum, espada envainada y posible casco representado por pequeños segmentos verticales.

\section{Conclusiones finales Estilo I (cuadro 3)}

Para determinar la posible panoplia del Estilo I a la vista de lo expuesto nos apoyaremos únicamente en las imágenes que representan escenas de enfrentamiento y de caza.

\section{- La panoplia}

Con los datos obtenidos en el estudio del armamento encontrado en los yacimientos vecinos al TSM ${ }^{3}$ y en el propio TSM con cronologías más o menos similares, podemos concluir que la panoplia que más se repite en las escenas de enfrentamiento es la formada por falcata y arma arrojadiza (jabalina) como elemento ofensivo y escudo (caetra/scutum) y quizás casco como elemento defensivo. Esto coincide con el armamento típico del s. III-II a.C. que aparece en los yacimientos estudiados, y con la opinión de Quesada que denomina a este periodo y para esta zona como «fase avanzada» o de «panoplia simplificada».

En las escenas de caza el elemento que se repite en todos los personajes es la jabalina, mientras que la panoplia completa (casco, espada, jabalina) sólo la presenta el único infante. El hecho de no portar más arma que jabalinas puede deberse a que esta actividad requiere largos desplazamientos y movimientos rápidos por lo que se necesita un tipo de arma ligera y práctica, susceptible de ser transportada sin demasiado esfuerzo y adecuada para el tipo de animal representado (venados, jabalíes). En nuestra revisión del poblado de La Bastida (Díes y Bonet, 1996; Díes, Bonet, Álvarez y Pérez, 1997), observamos que el número de regatones encontrados (53) triplicaba el número de puntas de lanzas (13), lo que nos llamó la atención puesto que es un elemento que por sí mismo no tiene funcionalidad, si no está unido a una

3 Revisado el armamento de los siguientes yacimientos: Tossal de Sant Miquel: s. III - s. II a.C. (Bonet, 1995:8182); Castellet de Bernabé: s. III - s. II a.C. (Guerin, 2003: 201-202); Puntal dels LLops: s. III - s. II a.C.(Bonet, 2002: 152-153); Corral de Saus: s. III a.C. -s. II a.C. (Izquierdo, 2000); La Bastida: S. IV a.C. - 325 a.C. (Fletcher, Plá y Alcácer, 1965-1969 vol. I y II; Díes, Bonet, Álvarez y Pérez, 1997); La Serreta: Poblado: s. III a.C. - inicios s. II a.C. (Grau y Reig, 2002-2003:106); Necrópolis: S. IV a.C. - primera mitad s. III a.C. (Reig, 2000).; L'Albufereta: s. IV a.C. - principios s. II a.C. (Verdú, 2005); Coimbra del Barranco Ancho: s. IV a.C. - principios s. II a.C. (García Cano, 1997); Cigarralejo: s. IV a.C. - I a.C. (Quesada, 2005:111-134); Cabecico del Tesoro: s. V a.C. - primera mitad s. I a.C. (Quesada:1989); Llano de la Consolación: s. V a.C. - segundo cuarto s. IV. (Valenciano, 2000); Cabezo Lucero: primera mitad s. V a.C. - finales segundo tercio s. IV (Aranegui et alii, 1993). 
lanza. En el poblado de la Serreta (Llobregat et alii, 1995; Grau Mira, 1996; Olcina et alii, 2000, en Grau y Reig, 2002-2003) sucedía algo parecido, pues el número de puntas de lanza (10) era la mitad que el de regatones (21). No ocurre lo mismo en las necrópolis, donde el número de regatones y puntas de lanza suele ser similar, como vemos en la misma necrópolis de la Serreta, (Reig, 2000) (17 puntas de lanza frente a 21 regatones). Las explicaciones podrían ser varias: que el regatón, la mayoría de las veces sin remaches, se desmontaba fácilmente del asta de madera; que en el momento de la huida los elementos metálicos (punta y regatón) de muchas de ellas se encontrasen sin montar y que los habitantes se llevasen algunas montadas y gran parte de las puntas por su valor frente a los regatones; o que por la misma razón, al llegar el momento del asedio, se «montasen» más puntas que regatones en las lanzas o jabalinas y que éstas se perdiesen arrojadas contra el enemigo; o que el propio enemigo se las llevase consigo. Recientemente Quesada ha propuesto también que no formaran parte de lanzas o jabalinas, sino de bastones (2010:27).

Otro aspecto interesante a destacar dentro de los vasos del Estilo I, es que los jinetes, que aparentemente serían personajes pertenecientes a las élites de la ciudad (Aranegui et alii, 1997a), no son los que aparecen mayoritariamente portando una panoplia completa. Habría que tener en cuenta que mayoritariamente aparecen realizando una actividad cinegética, que sí es propia de este grupo social, y que el cazador no necesita de una panoplia excesivamente compleja. Efectivamente en escenas diferentes a las de caza, sólo encontramos a los jinetes en dos ocasiones: un gran personaje desmontado, con una panoplia completa (casco, espada, caetra y jabalina) (vaso $\mathrm{n}^{\mathrm{o}} 122$ ), que parece enfrentarse sólo contra dos embarcaciones repletas de hombres. En la otra escena el guerrero (vaso ${ }^{\circ} 222$ ) parece esgrimir una falcata en una difícil posición y en una actitud ofensiva imposible, montado sobre su caballo y con la intención de atacar con su arma a un enemigo situado a bastante distancia.

\section{EstiLo II (cuadro 5)}

En los 24 vasos correspondientes al Estilo II con presencia de personajes armados encontramos 30 escenas: ocho de enfrentamiento con 17 personajes (12 completos), dos de desfile con 5 personajes completos, una posible escena de caza con dos personajes completos, una escena de parada con 12 personajes (11 completos), y 18 indeterminables con 40 personajes (21 completos).

Cuadro 5. Tipología de escenas, repetición y número de personajes en el Estilo II.

\begin{tabular}{|l|c|c|}
\cline { 2 - 3 } \multicolumn{1}{c|}{} & $\mathbf{N}^{\mathbf{0}}$ ESCENAS & $\mathbf{N}^{\mathbf{0}}$ PERSONAJES \\
\hline ENFRENTAMIENTO & 8 & 17 \\
\hline DESFILE & 2 & 5 \\
\hline CAZA & $1 ?$ & 2 \\
\hline PARADA & 1 & 12 \\
\hline INDETERMINABLE & 18 & 40 \\
\hline TOTAL & 30 & 76 \\
\hline
\end{tabular}

\section{Las armas y su representación en el Estilo II.}

Como hemos comentado al hablar del Estilo I, debemos ser prudentes al diferenciar los distintos tipos de armas que aparecen en estos vasos, por las razones ya expuestas. Sin em- 
bargo, en el Estilo II su dibujo es más correcto y completo ${ }^{4}$; aunque, junto a dibujos claros, encontramos también otros donde la representación del armamento se realiza de forma burda e imprecisa ${ }^{5}$. (Ver cuadro 6).

Cuadro 6. Asociaciones de armas en el Estilo II

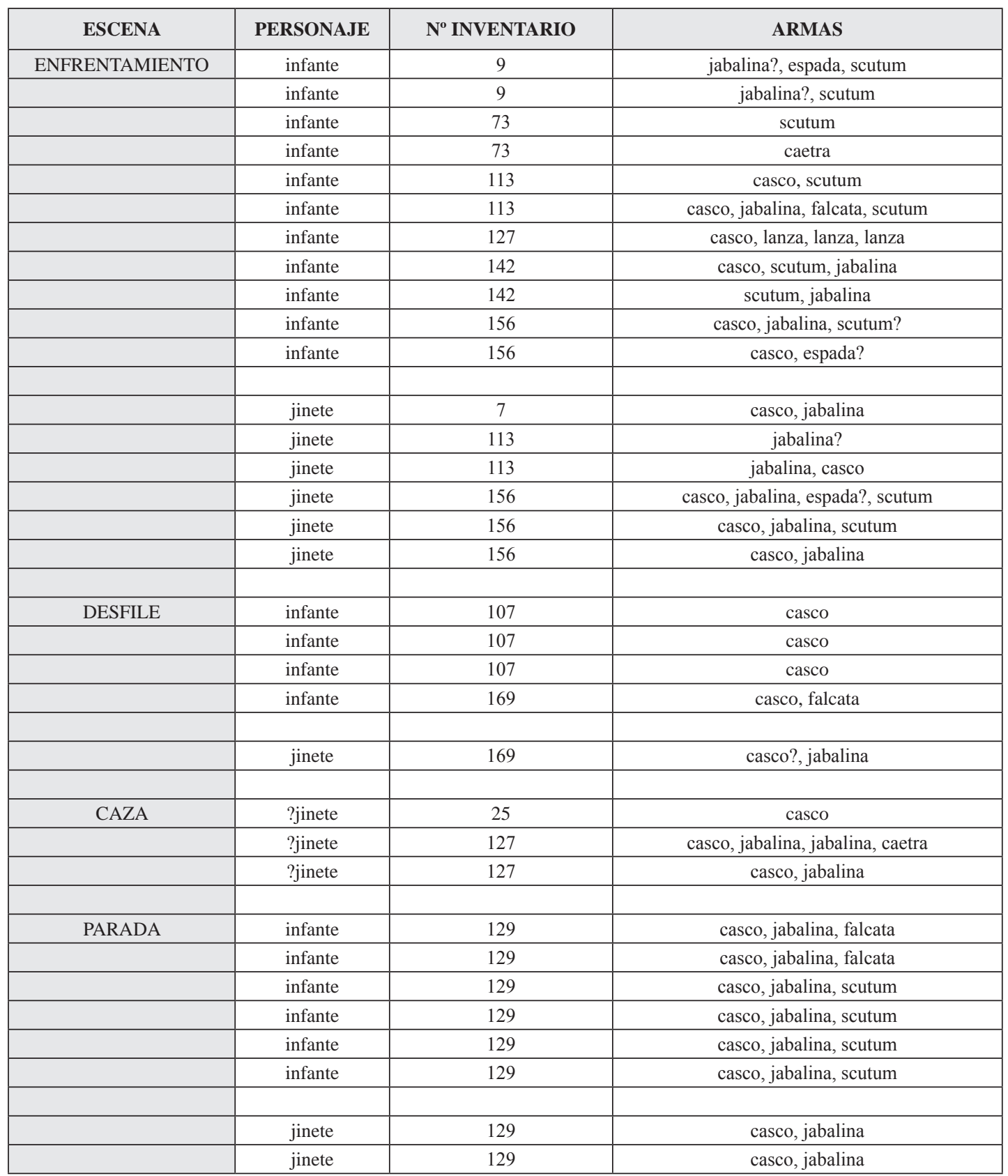

4 Ver vaso $\mathrm{n}^{\mathrm{o}} 16$ donde se dibuja perfectamente un casco Montefortino.

5 Ver vaso $n^{\circ} 156$, las armas que presentan los personajes están burdamente definidas. 


\begin{tabular}{|c|c|c|c|}
\hline \multirow[t]{5}{*}{ ESCENA } & PERSONAJE & No INVENTARIO & ARMAS \\
\hline & jinete & 129 & casco, jabalina \\
\hline & jinete & 129 & casco, jabalina \\
\hline & jinete & 129 & casco, jabalina \\
\hline & jinete & 129 & casco, jabalina \\
\hline & & & \\
\hline \multirow[t]{40}{*}{ INDETERMINABLE } & remero & 10 & casco \\
\hline & remero & 10 & casco \\
\hline & remero & 10 & casco \\
\hline & remero & 10 & casco \\
\hline & indeterminable & 16 & casco \\
\hline & indeterminable & 17 & casco \\
\hline & indeterminable & 17 & casco \\
\hline & infante & 17 & lanza?, caetra \\
\hline & jinete & 25 & casco \\
\hline & infante & 31 & casco, lanza \\
\hline & infante & 148 & casco, jabalina \\
\hline & infante & 148 & casco \\
\hline & infante & 148 & casco, jabalina, jabalina \\
\hline & infante & 148 & casco \\
\hline & infante & 148 & casco \\
\hline & infante & 148 & casco, jabalina \\
\hline & infante? & 149 & casco, lanza?, scutum, coraza \\
\hline & infante & 149 & casco, falcata, scutum \\
\hline & infante & 149 & casco, jabalina \\
\hline & infante & 181 & lanza?, falcata \\
\hline & jinete & 17 & casco \\
\hline & jinete & 31 & casco \\
\hline & jinete & 46 & casco, jabalina \\
\hline & jinete & 108 & casco \\
\hline & jinete & 121 & casco, jabalina \\
\hline & jinete & 121 & casco \\
\hline & jinete & 127 & casco \\
\hline & jinete & 127 & casco, jabalina, scutum \\
\hline & jinete & 138 & casco, jabalina \\
\hline & ?jinete & 142 & casco, jabalina \\
\hline & ?jinete & 142 & casco \\
\hline & ?jinete & 142 & casco, jabalina \\
\hline & jinete & 149 & casco, jabalina \\
\hline & jinete & 149 & casco, jabalina \\
\hline & jinete & 151 & jabalina, casco, coraza? \\
\hline & jinete & 151 & casco, jabalina \\
\hline & jinete & 151 & casco, jabalina \\
\hline & jinete & 157 & jabalina? \\
\hline & jinete & 157 & lanza? \\
\hline & jinete & 157 & jabalina? \\
\hline
\end{tabular}




\section{a) Armas ofensivas:}

- Falcata: representada por sí misma o por su vaina sujeta al cinto, con doble filo, uno recto y otro curvo; siempre aparece en manos de infantes. No es posible determinar su tipología atendiendo a la empuñadura; la mayoría de las veces el autor parece reflejar una representación libre de lo que es este tipo de arma.

- Espada: se representa con dos filos rectos por sí misma o en su vaina sujeta al cinto. Igual que con las falcatas es muy aventurado establecer su tipología. Quesada propone una espada de antenas atrofiadas en el vaso $n^{\circ} 9$ (Quesada, 1997:240). Las espadas rectas de antenas son muy infrecuentes en territorio ibérico en el s. III-II a.C. (Quesada, 1997:240). También encontramos espadas con estilo poco cuidado como en el caso de las falcatas ${ }^{6}$.

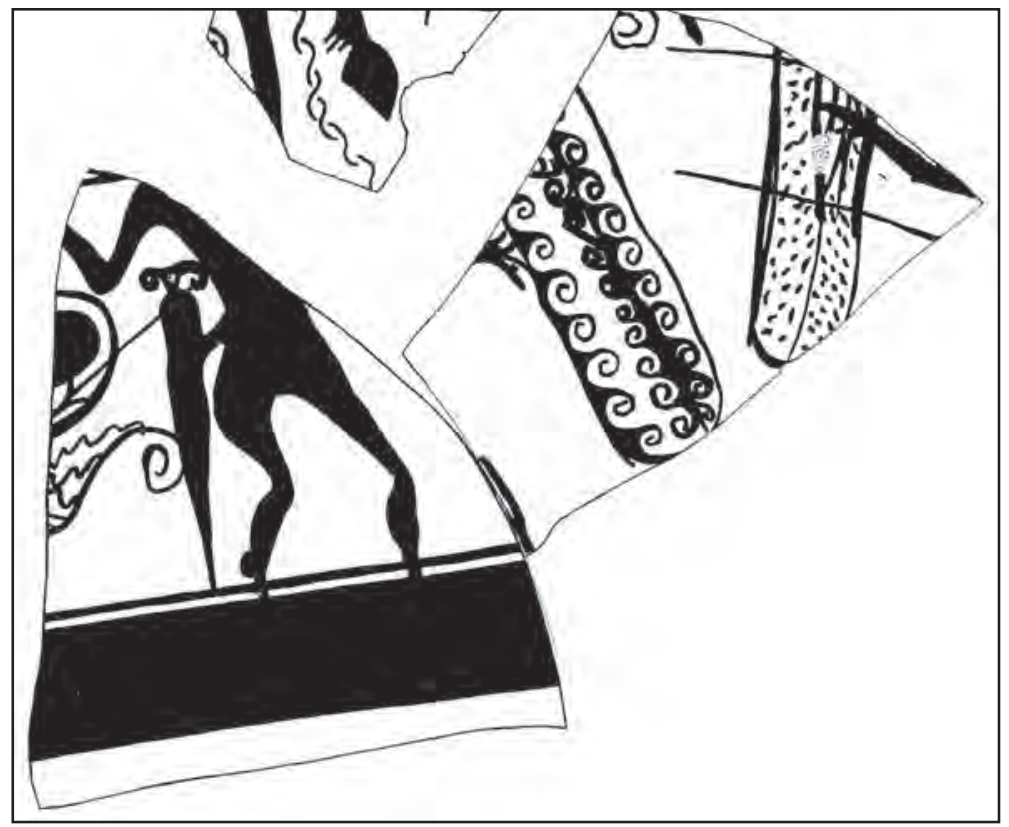

Figura 11. Vaso 9 Archivo Dpto. Prehistoria y Arqueología (UVEG).

- Armas de astil: lo mismo que en el Estilo I, hemos diferenciado entre lo que es un arma arrojadiza, de las que no lo son. En ocasiones el regatón se ha representado como una granada sin que la arqueología haya proporcionado evidencias reales de que existieran así en la realidad ${ }^{7}$ (Quesada, 1997: 414).

\section{b) Armas defensivas:}

- Caetra: escudo circular representado de frente en todos los casos mostrando su parte exterior, y con efecto radiografiado en una ocasión mostrando la mano y las anillas

\footnotetext{
6 Ver vaso $n^{\circ} 156$.

7 Ver vaso $n^{\circ} 149$ donde las armas arrojadizas acaban en forma de corazón u hoja.
} 
(vaso $\mathrm{n}^{\circ} 73$ ). Están adornados con dibujos que parecen grandes rosetas. Sólo aparecen en 3 ocasiones aunque posiblemente en solo dos vasos 17-73 y 127.

- Scutum: escudo de forma cuadrada u ovalada que en este estilo aparece de forma mayoritaria (en 17 ocasiones), aunque los encontramos compartiendo escenas con los anteriores. Arma defensiva que se extiende por el mundo helenístico mediterráneo desde el s. V a.C. y en Iberia es propio de la fase avanzada de la panoplia que corresponde a los s. III-I a.C. En el propio TSM se encontró un gran umbo circular, probablemente perteneciente a un scutum (Bonet, 1995:81-82). Lo encontramos en manos de infantes en 14 ocasiones y en dos casos portado por jinetes.

- Casco: a diferencia de las prevenciones con que hemos abordado los casos dibujados en el Estilo I, en el Estilo II tan sólo tenemos un interrogante al respecto en el vaso $\mathrm{n}^{\mathrm{o}} 7$ que suscita la duda de si se trata de su propio cabello o es un casco terminado en pequeños segmentos o trazos. Respecto al diseño de los mismos, se encuentran representados en una amplia variedad propia de los s. IV al II a.C.: con cresta, cimera, penacho, casquete, Montefortino e incluso con cuernos.

- Coraza: hemos señalado una posible coraza en el vaso $n^{0} 151$, que se distingue a través de pequeños segmentos que recorren el tórax del guerrero sobre un fondo oscuro. Otro personaje también en este vaso porta una posible coraza de malla, aunque con prevenciones porque la arqueología no proporciona ningún hallazgo de este tipo de material para esta época. Otros tipos de protección corporal podrían ser de materiales orgánicos como el cuero o el lino (Quesada, 1997:582).

\section{Escenas y acciones en el Estilo II (cuadro 6).}

Dentro del Estilo II hemos encontrado escenas de enfrentamiento, desfile, parada, una posible escena de caza y otras indeterminables.

- Enfrentamiento: cuando uno o más personajes aparece en actitud de lucha y descartamos que se trate de una escena de caza por la posición de las armas (vaso $n^{\circ} 7$ ) o porque en la escena no aparece ningún animal susceptible de ser atacado.

- Caza: uno o más personajes armados se enfrentan a animales salvajes. Puede confundirse con una escena de enfrentamiento (vaso $\mathrm{n}^{\mathrm{o}} 127$, dos personajes, uno de ellos con una caetra, parece que se enfrentan a un animal salvaje que aparece incompleto).

- Desfile: en este grupo incluimos aquellos personajes masculinos que portan algún tipo de arma y comparten escenas con personajes femeninos y músicos. No aparece en el Estilo I.

Parada: los distinguimos del grupo anterior porque, si bien desfilan armados, esta acción puede tener una connotación militar, sin ninguna presencia femenina. No aparece en el Estilo I.

- Indeterminable: en este grupo (con 40 personajes) incluimos aquellos personajes armados que por estar incompletos o por no poder distinguir su acción no conocemos qué tipo de escena desarrollan, así como aquellos armados que aparecen embarcados (vaso $\left.\mathrm{n}^{\mathrm{o}} 10\right)$.

Los personajes representados en las distintas escenas pertenecen a las siguientes acciones (ver cuadro 7): 
Cuadro 7. número de infantes y jinetes representados en las diferentes escenas del Estilo II.

\begin{tabular}{|c|c|c|c|c|c|}
\hline \multicolumn{3}{|l|}{ Escena } & Infantes & Jinetes & TOTAL \\
\hline \multicolumn{3}{|l|}{ Enfrentamiento } & 11 & 6 & 17 \\
\hline \multicolumn{3}{|l|}{ Desfile } & 4 & 1 & 5 \\
\hline \multicolumn{3}{|l|}{ Caza? } & & 2 & 2 \\
\hline \multicolumn{3}{|l|}{ Parada } & 6 & 6 & 12 \\
\hline \multirow{2}{*}{ Indeterminable } & Remeros & Indeterminables & \multirow{2}{*}{12} & \multirow{2}{*}{21} & \multirow{2}{*}{40} \\
\hline & 4 & 3 & & & \\
\hline TOTAL & 4 & 3 & 33 & 37 & 76 \\
\hline
\end{tabular}

Como sucedía en el Estilo I, son más numerosos los personajes relacionados con enfrentamientos, aunque aparecen otros en desfiles y paradas, escenas propias del Estilo II y ausentes en el Estilo I.

Respecto al tipo de personaje representado son más numerosos los jinetes en el Estilo II, que en el Estilo I, donde además sólo estaban relacionados con escenas de caza. De ellos 33 (uno dudoso) son infantes (43,42\%); 36 jinetes (6 de ellos con dudas) $(47,36) ; 4$ remeros $(5,26 \%)$ y 3 indeterminables $(3,94 \%)$.

\section{La panoplia representada en el Estilo II.}

De la misma manera que en el Estilo I hemos realizado las asociaciones de armas de este grupo, referidas a los personajes cuyas figuras están completas, estableciendo una distinción entre la panoplia de infantes y de jinetes. Igualmente, los personajes indeterminables por incompletos o aquellos que han perdido parte de su dibujo, los utilizamos para completar la información que nos proporcionan los que tienen la figura completa.

Como en el Estilo I, encontramos una gran variedad de asociaciones de armas dentro de cada grupo de escenas, por lo que resulta difícil, en un primer momento, asignar una panoplia típica para cada una de ellas.

\section{Escenas de enfrentamiento:}

Tras el recuento de armas de los personajes completos observamos que 7 infantes portan armas ofensivas y defensivas (vasos $\mathrm{n}^{\mathrm{o}} 113,127,142$ y 156), 4 jinetes presentan armas ofensivas y defensivas (vasos $n^{0} 113$ y 156) y uno de ellos sólo presenta un arma ofensiva. Si tenemos en cuenta a las figuras incompletas de infantes, la panoplia parece formada por jabalina, casco y scutum.

Los jinetes llevan un arma arrojadiza (jabalina) y dos de ellos además se defienden con scutum. El jinete del vaso $\mathrm{n}^{\mathrm{o}} 156$ presenta una panoplia completa (casco, jabalina, vaina de espada y scutum, al igual que el infante del vaso $n^{\circ} 113$ (casco, jabalina, falcata, scutum),

El vaso $n^{\circ} 151$, que Aranegui define como de desfile (Aranegui et alii, 1997a:63), nos aporta información valiosa ya que de nuevo aparece la panoplia formada por el dúo jabalina y casco en los tres jinetes, y en el primero además hemos señalado una posible coraza de malla.

La presencia en jinetes de scutum la hallamos también en representaciones coetáneas o algo más tardías como exvotos de bronce del Santuario de la Luz (Murcia), o en estelas aragonesas y catalanas. En el vaso $\mathrm{n}^{\circ} 113$ un posible jinete desmontado porta una panoplia completa: 
arma arrojadiza, falcata, casco y scutum. Podría responder a lo que conocemos sobre la costumbre de los iberos de acudir a la lucha en caballo y desmontar para luchar cuerpo a cuerpo. Si esto fuera así confirmaría, como hemos apuntado repetidamente, que los guerreros líderes o de estatus superior son jinetes, como nos señalan los hallazgos arqueológicos del s. IV y principios del s. III a.C. de la Serreta tumba no 1 y 53 (Reig, 2000:116), (Moltó y Reig, 1996:121) y El Cigarralejo, tumbas $n^{\circ} 103,200,277,301$ (Quesada, 2005b: 130-132); y que continuará de esta manera en momentos posteriores, de fines del s. III a. C. y principios del s. II a.C.

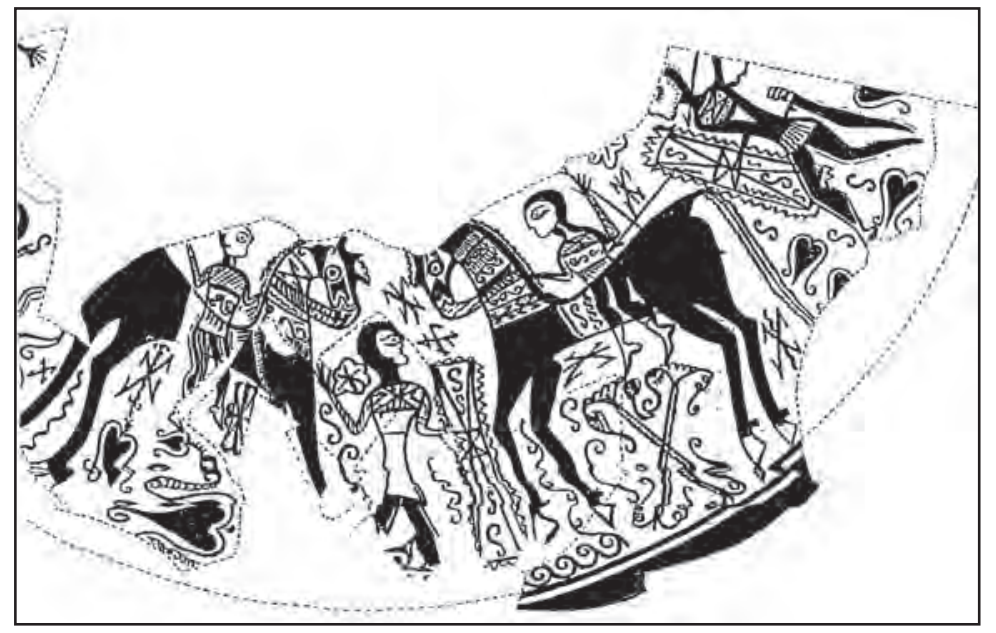

Figura 12. Vaso 113 Archivo Dpto. Prehistoria y Arqueología (UVEG).).

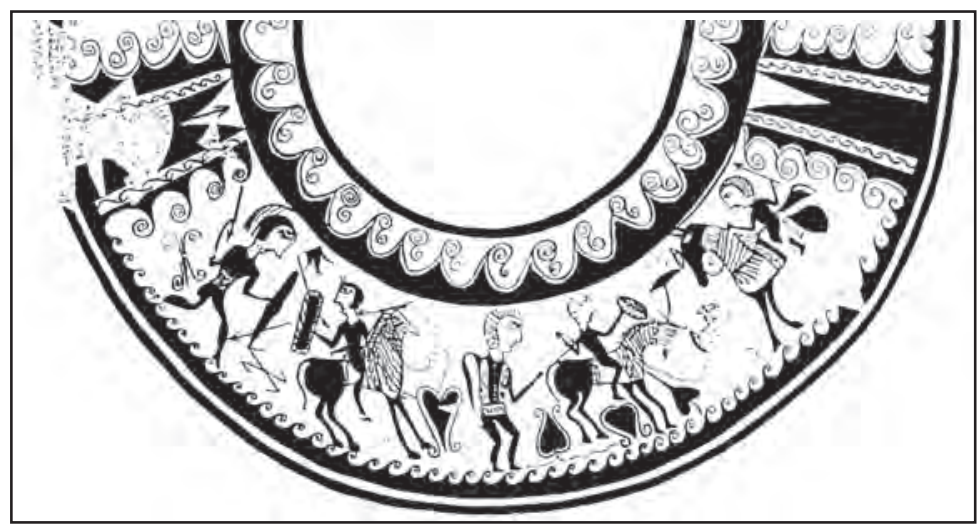

Figura 13. Vaso 156 Archivo Dpto. Prehistoria y Arqueología (UVEG).

\section{Escenas de desfile.}

Encontramos dos escenas de desfile con cinco personajes, todos ellos de figura completa, cuatro infantes y un jinete. La escena del vaso $\mathrm{n}^{\mathrm{o}} 107$ nos muestra una panoplia compuesta únicamente por el casco, elemento repetido en todos sus personajes (Aranegui la señala como una comitiva de músicos (Aranegui et alii, 1997a:93), y en el vaso n ${ }^{\circ} 169$ dos personajes van armados con jabalina y falcata. 


\section{Escenas de caza.}

A diferencia de lo que vimos en el Estilo I, en la presunta escena de caza del Estilo II (vaso $\mathrm{n}^{\circ}$ 127) no aparecen animales heridos, ni tampoco vemos a ninguno completo compartiendo escena con los personajes. Pero de la actitud de las figuras y por presentarse más de un personaje en la misma escena, hemos deducido que podría tratarse de caza o al menos de enfrentamiento con un animal, a diferencia de lo que vemos en los vasos $\mathrm{n}^{\mathrm{o}} 25$ y 138, que representan escenas de heroicidad o mito (Kurtz, 1993:242-243), y que hemos situado en el grupo «indeterminable». Se trata de un jinete desmontado y un jinete sobre un caballo, ambos con casco y armas arrojadizas (jabalinas) y lo que más llama la atención es la caetra de gran tamaño que porta el primer personaje. Como conclusión a la panoplia de este grupo podemos decir que los «cazadores» portarían armas arrojadizas principalmente, y se tocan con casco. El personaje desmontado es la excepción, pero podría tratarse de un personaje de linaje que porta la panoplia completa de guerrero.

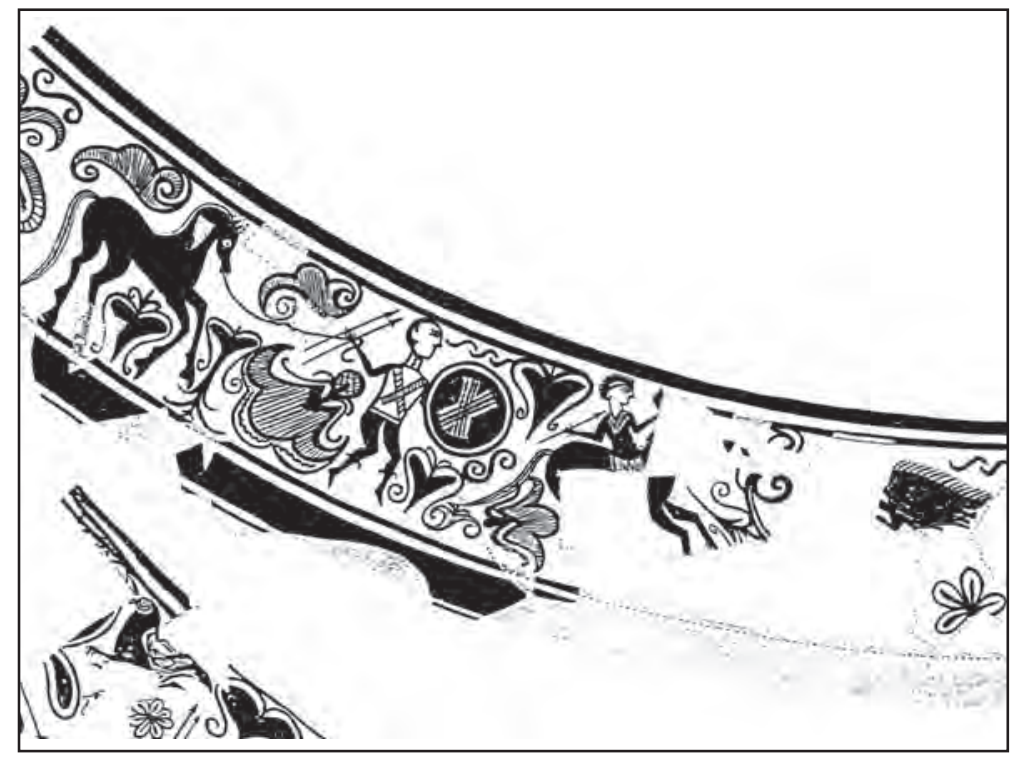

Figura 14. Vaso 127 Archivo Dpto. Prehistoria y Arqueología (UVEG).

\section{Escenas de parada.}

La única escena de parada está en el vaso $\mathrm{n}^{\circ} 129$ ó «Vaso de los guerreros». Son doce personajes: seis infantes y seis jinetes. Lo primero que salta a la vista es la uniformidad de la panoplia: infantes: dos asociaciones compuestas por casco, jabalina y falcata y cuatro asociaciones compuestas por casco, jabalina y scutum. Los jinetes presentan una homogeneidad total, los seis portan únicamente casco y jabalina. 


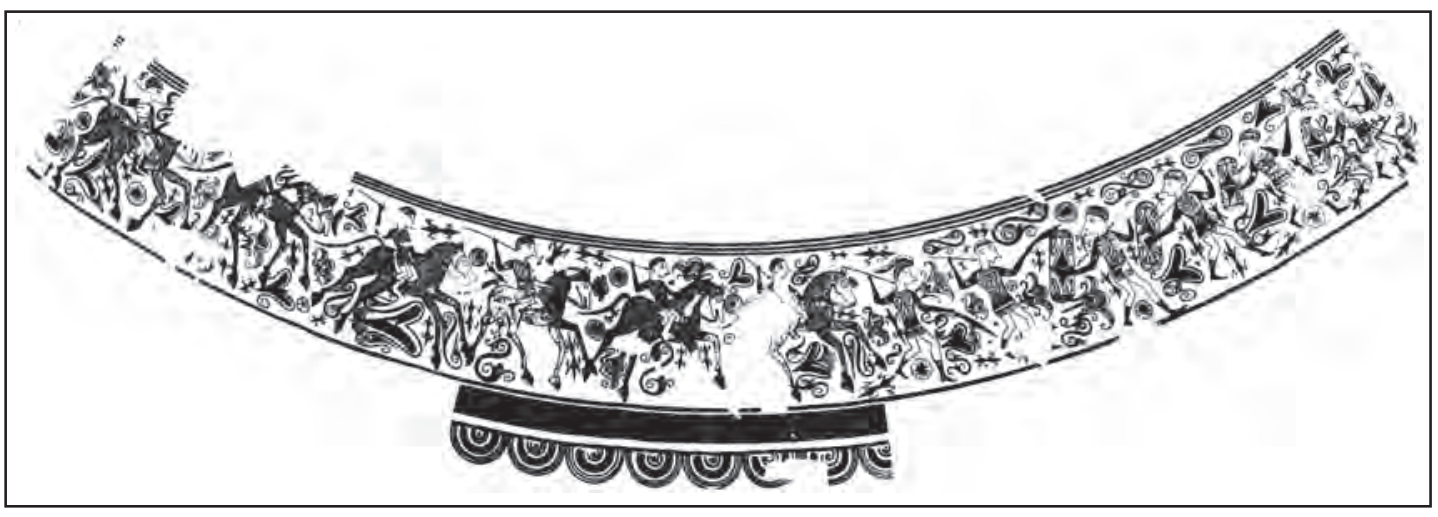

Figura 15. Vaso 129 Archivo Dpto. Prehistoria y Arqueología (UVEG).

5. Escenas indeterminables.

Comprende 18 escenas indeterminables con 40 personajes (cuatro remeros, tres indeterminables, 12 infantes y 21 jinetes). El armamento que aparece en los personajes de este tipo de escena sólo podemos utilizarlo como complemento de la información procedente de los otros grupos ya que puede alterar los resultados sin aportar datos seguros.

En el grupo de remeros (vaso $\mathrm{n}^{\mathrm{o}} 10$ ) sólo tenemos una figura completa, pero en todos ellos se constata claramente que se tocan con un casco por lo que los hemos incluido en nuestro trabajo como personajes armados. No podemos añadir ninguna conclusión a la vista de este dibujo aunque nos llama la atención que un grupo de hombres embarcados porten cascos a no ser que estén dispuestos a entrar en algún tipo de enfrentamiento, con las armas situadas en la parte baja de la embarcación mientras ocupan sus manos remando hacia un objetivo.

Del grupo de los indeterminables nos interesa principalmente el personaje del fragmento $\mathrm{n}^{\circ} 16$, porque muestra un casco de tipo Montefortino dibujado a la perfección, propio de la llamada «fase avanzada» o «panoplia simplificada» que discurre entre el s. III a.C. hasta el I a.C., y que proviene del mundo itálico. Los personajes del vaso $\mathrm{n}^{\mathrm{o}} 17$ también portan cascos, probablemente orgánicos con terminaciones en ondas que imitan el pelo.

El siguiente grupo está formado por infantes armados (12 en total) que representan diversas acciones. El grupo del vaso $\mathrm{n}^{\mathrm{o}} 148$ podría estar interpretando una acción de cortejos y danzas (Aranegui et alii, 1997a:94), todos ellos portan casco, dos de cresta, y tres presentan la asociación casco y jabalina, que como hemos visto se repite en la panoplia de otros grupos, un personaje, además parece portar una jabalina en cada mano. Y el grupo del vaso $\mathrm{n}^{\mathbf{0}} 149$ parece que está representando una danza (Aranegui et alii, 1997a:90) o bien una demostración de lucha; portan, el primero lanza, casco y scutum y el segundo falcata, scutum y casco, panoplia que ya hemos visto anteriormente. El tercer infante de este grupo parece pasear con una jabalina al hombro y está tocado con casco en actitud de movimiento o paseo mientras que los dos jinetes de este grupo, portan jabalina y casco y no llevan scutum. Otro infante muestra una vaina de falcata y una posible lanza.

Los vasos $\mathrm{n}^{\mathrm{o}} 25$ y 138 pueden interpretarse como el relato del mito, poema o similar del héroe que lucha contra un animal monstruoso, tal vez un lobo (Kurtz, 1993:242-243). En definitiva podemos afirmar que muestra las mismas armas que los personajes que aparecen cazando: un casco y una jabalina. Igualmente ocurre con los personajes del vaso $\mathrm{n}^{\mathrm{o}} 142$ que hemos incluido en este apartado porque no podemos asegurar que se trate de una escena de 


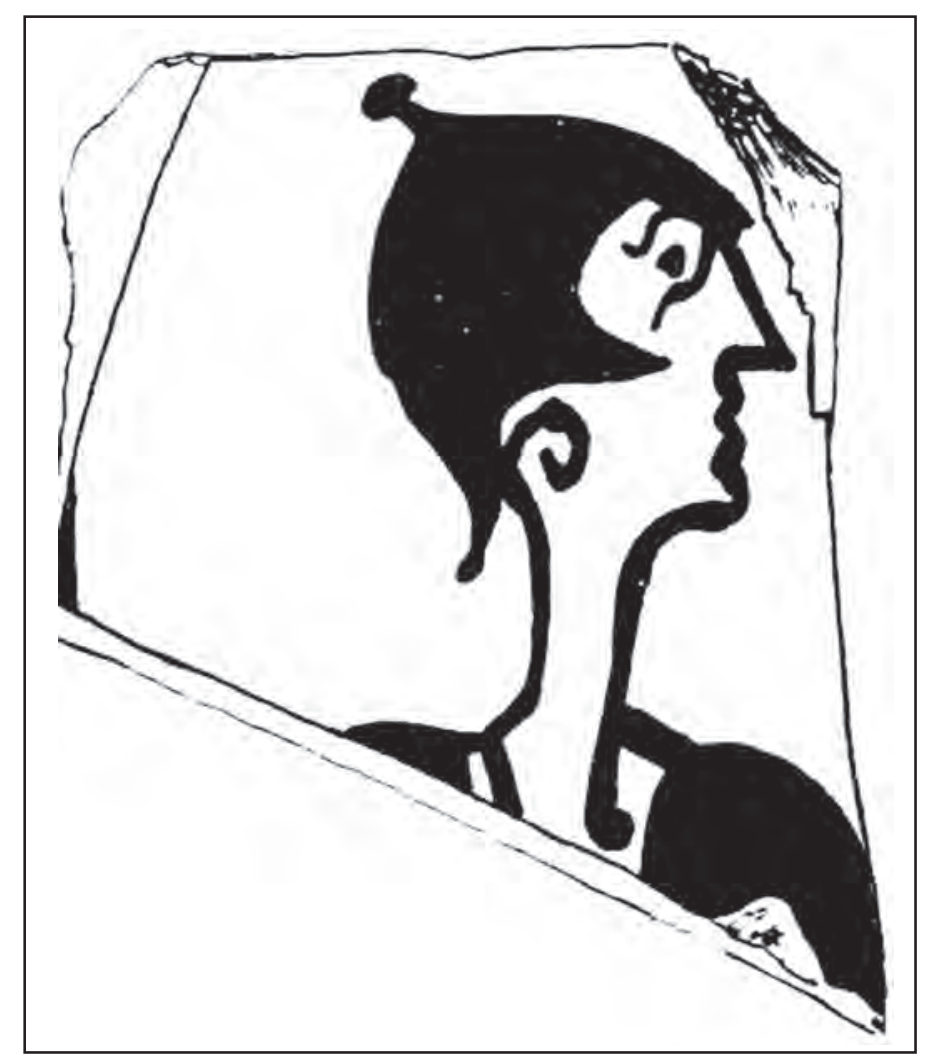

Figura 16. Vaso 16 Archivo Dpto. Prehistoria y Arqueología (UVEG).

enfrentamiento o de caza. Son personajes que van tocados con casco y muestran jabalinas en actitud de lanzamiento.

Los jinetes del vaso $\mathrm{n}^{\mathrm{o}} 151$ podrían representar una escena de caza, de enfrentamiento o de exhibición. Nos interesa resaltar nuevamente la panoplia del jinete compuesta por casco y jabalina. Excepcionalmente se ha interpretado la malla del personaje como una coraza, aunque la arqueología no pueda avalar esta teoría (Quesada, 1997:582). Vuelven a mostrarnos unos personajes montados que sólo llevan un arma de astil (son figuras incompletas que pueden añadir a su panoplia un casco).

\section{Conclusiones del Estilo II.}

\section{- La panoplia}

En las escenas de enfrentamiento, lo primero que observamos es el predominio del arma de astil «jabalina» sobre el resto de armas, sobre todo en el caso de los jinetes (100\%). La falcata, sin embargo, solo la encontramos en una ocasión, y la espada en tres ocasiones. Lo que destacamos en este caso es que tanto la falcata como la espada no aparecen nunca como único elemento de la panoplia, sino que lo hacen en asociación de arma de astil y de scutum, y en este grupo siempre aparece envainada: todos los personajes la portan sujeta al cinto y en actitud de ataque con el arma de astil. Ésta, el arma de astil, está representada 12 veces como 
jabalina y tres veces como lanza, en una asociación triple. Otro aspecto a destacar es la casi ausencia del elemento defensivo caetra, y el predominio del arma defensiva scutum (diez veces, uno dudoso) en un total de 17 personajes. Esta panoplia es la que Quesada encuadra en la «fase avanzada» o «panoplia simplificada», que discurre desde el último tercio del s. III a.C. al s. I a.C. Esta información coincide con los hallazgos de los yacimientos estudiados correspondientes a los s. III-II a.C. (Corral de Saus, parte de L'Albufereta, parte de Coimbra del Barranco Ancho, parte del Cigarralejo) en los que vemos una disminución de elementos de la panoplia con respecto a lo que se encontraba en yacimientos de cronología anterior. Lo que no es coincidente con este periodo es el uso de doble o triple arma arrojadiza, propio de un periodo anterior s. IV a.C. - último tercio del s. III a.C.

Respecto a las dos escenas de desfiles, el vaso $n^{\circ} 107$ lo hemos incluido en este estudio porque van tocados con cascos aunque no portan ningún otro tipo de arma, lo que puede explicarse por la presencia de mujeres en la escena o por el carácter festivo del acto. En el vaso $\mathrm{n}^{\mathrm{o}}$ 169 un jinete muestra una jabalina en actitud de ser arrojada y un infante presenta una falcata envainada sujeta al cinto, tocados ambos por dos cascos.

La única escena de parada cuidadosamente elaborada (vaso $n^{\circ} 129$ ), nos aporta una información relevante. En ella encontramos una panoplia homogénea, similar a la que aparece en las escenas de enfrentamiento, con la única diferencia de que ningún jinete porta scutum. Esta

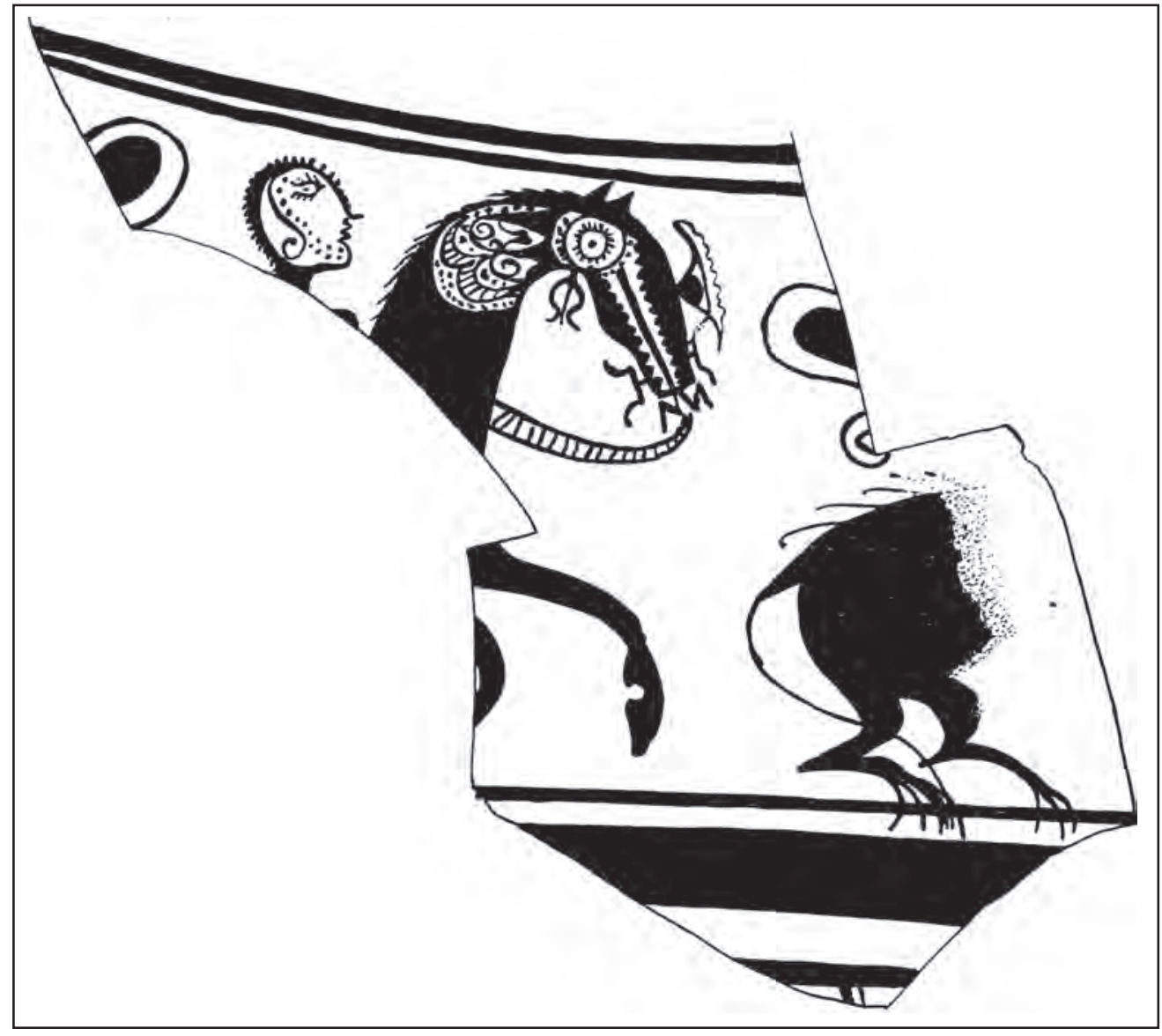

Figura 17. Vaso 25 Archivo Dpto. Prehistoria y Arqueología (UVEG). 
panoplia coincide totalmente con la característica de la «fase avanzada»o «simplificada» de los s. III-I a.C. y es más completa que la que hemos visto en los desfiles. También destacamos que en esta escena de parada ningún personaje sobresale de los demás, a excepción del que porta un casco con una gran cresta, aunque bien podría tratarse de un recurso del artista para rellenar un hueco entre el resto de elementos que rodean al personaje.

En la única posible escena de caza (como tal) la panoplia no es homogénea como ocurría en el Estilo I. Desconcierta el hecho de que un jinete desmontado se enfrente a un animal con una caetra y dos lanzas en la misma mano. Sin embargo no descartamos que sea una escena heroica del tipo de los vasos $n^{\circ} 25$ y 138, aunque con la diferencia de que, en vez de un ser mitológico/heroico, se trate de dos protagonistas en lucha conjunta contra un animal monstruoso. Si se trata de una escena heroica, debemos plantearnos si lo que representan son cazadores o guerreros. Si es esto último es extraño que no lleve ninguna otra arma ofensiva, tal vez un puñal o una espada.

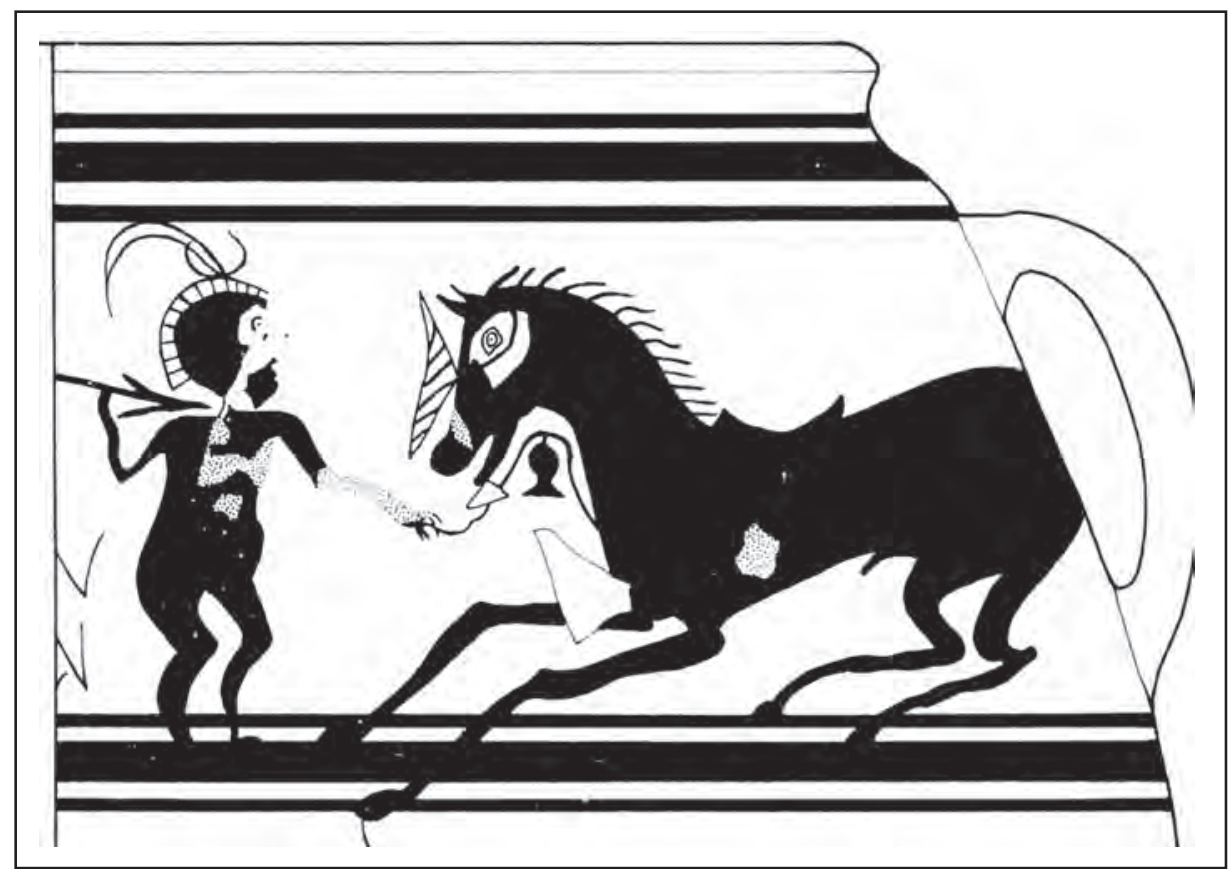

Figura 18. Vaso 138 Archivo Dpto. Prehistoria y Arqueología (UVEG).

\section{Conclusiones finales Del tRabajo}

Después del estudio de las armas representadas en los vasos con decoración figurada del TSM, comparado con los resultados obtenidos del análisis de los yacimientos vecinos, y con la información publicada sobre la panoplia ibérica por F. Quesada hemos llegado a las siguientes conclusiones: 


\section{Escenas y personajes en los Estilos I y II.}

Cuadro 8. Contabilización del número de escenas en cada estilo.

\begin{tabular}{|l|c|c|}
\cline { 2 - 3 } \multicolumn{1}{c|}{} & Estilo I & Estilo II \\
\hline Enfrentamiento & 8 & 8 \\
\hline Caza & 6 & 1 \\
\hline Doma & 2 & 0 \\
\hline Desfile & 0 & 2 \\
\hline Parada & 0 & 1 \\
\hline Indeterminable & 3 & 18 \\
\hline
\end{tabular}

Basándonos en los tipos de escenas que se han querido representar sobre los vasos del TSM, en una primera valoración, podemos comprobar que parece que ambos estilos obedecen a motivos distintos a la hora de ejecutarse. El Estilo I muestra la vida diaria, cotidiana, con escenas de caza, doma y enfrentamientos cruentos. El Estilo II por el contrario relata y se recrea en costumbres, ritos, fiestas del pueblo edetano, especialmente de la élite con escenas de desfile, parada, lucha y originales enfrentamientos individuales contra monstruos o grandes animales, con ausencia de escenas de cacería y domésticas. Sin embargo los enfrentamientos se dan en ambos estilos.

Cuadro 9, Contabilización del número de personajes por escena.

\begin{tabular}{|l|c|c|c|}
\hline Estilo I & Infantes & Jinetes & Indeterminables \\
\hline Enfrentamiento & 18 & 2 & \\
\hline Caza & 2 & 8 & \\
\hline Doma & 2 & 2 & \\
\hline
\end{tabular}

\begin{tabular}{|l|c|c|c|}
\hline Estilo II & Infantes & Jinetes & Indeterminables \\
\hline Enfrentamiento & 11 & 6 & \\
\hline Desfile & 4 & 1 & \\
\hline Caza & & 2 & \\
\hline Parada & 6 & 6 & \\
\hline
\end{tabular}

A la vista del cuadro 9 comprobamos los siguientes hechos: que infantes y jinetes se repartes desigualmente en ambos estilos; en escenas de enfrentamiento (Estilo I) el número de infantes es superior al de jinetes. Ocurre lo mismo en las escenas de desfile para el Estilo II. Los jinetes predominan en cambio en las en las escenas de caza. Estas representaciones obedecerían a una realidad social: que habría una mayor proporción de guerreros a pie, frente a los jinetes pertenecientes a las elites del poblado. La caza sería pues actividad propia (que no exclusiva) de la elite poseedora de caballos. ${ }^{8}$

En las escenas de desfile predominan los infantes, bailando y acompañados de músicos. En este caso la presencia de jinetes es complicada, probablemente por la dificultad que supone integrarlos en la coreografía de las danzas.

8 Recordamos también (vid supra pág. 21 la peculiar representación cinegética del Estilo II (vaso $n^{\circ}$ 127) donde más que ver cazar a un animal, parece reflejarse un enfrentamiento simbólico o de rito de paso de personajes importantes edetanos (Aranegui et alii, 1997a; Kurtz, 1993). 
En la escena de parada (vaso $n^{\circ} 129$ ) el número se iguala, quizás por su carácter militar. Aunque es posible también que la igualdad del número en este caso corresponda a una idea de simetría que el artista ha querido plasmar en la representación de esta escena.

\section{Armas ofensivas y defensivas en los Estilos I y II.}

Lo primero que tenemos que decir es que no existe ningún elemento armamentístico definitivo que determine una diferencia clara entre ambos estilos. Existen detalles que los separan que vamos a ver a continuación.

Del análisis del armamento ofensivo, deducimos que entre las armas envainadas, prácticamente no hay representaciones de puñales, pues solo aparece una imagen en el Estilo I (vaso $\mathrm{n}^{\mathrm{o}}$ 125). La explicación podría estar en que es un arma multiusos, no claramente asociada a combate/caza/parada y por consiguiente no se ha considerado suficientemente representativa del estatus del personaje que aparece representado con ella. Llama la atención que en el poblado de La Bastida de Les Alcuses (Moixent), donde la deposición de armas no es intencionada, se encontró un gran número de puñales, a diferencia de su escasez en las necrópolis, lo que viene a confirmar lo dicho anteriormente, su poco valor representativo de la clase social de su propietario, a diferencia de otras armas, como las lanzas o falcatas, con gran presencia en necrópolis.

La falcata o su vaina aparece en 12 ocasiones en el Estilo I, predominantemente en escenas de enfrentamiento y en 5 ocasiones en el Estilo II, tanto en enfrentamientos, como en desfiles o paradas. Es curioso que su representación sea menor en el Estilo II, donde aparecen más escenas que retratan la vida de las clases más acomodadas, cuando se considera este arma como símbolo de prestigio precisamente de estas gentes. Si nos basamos en los hallazgos arqueológicos de las necrópolis estudiadas, vemos que la falcata está más presente en las tumbas correspondientes a los s. IV a.C. - principios III a.C., y va disminuyendo a partir del s. III a.C. hasta llegar al s. I a.C. cuando en la mayoría de los enterramientos sólo aparece un arma, normalmente una lanza. Por lo que apuntamos que la escasez de falcatas en el Estilo II, podría deberse a una cronología algo más tardía para estas representaciones.

La espada la encontramos prácticamente el mismo número de veces en ambos estilos (4 veces en el Estilo I y 3 en el Estilo II) repartidas en el Estilo I en escenas tanto de caza como de enfrentamiento; en el Estilo II sólo en escenas de enfrentamiento, en personajes que utilizan otra arma para el ataque, la jabalina. No se puede decir con exactitud a la vista de los dibujos el tipo de espada que se representa.

Respecto a las armas de astil, las más frecuentes, hemos distinguido entre aquéllas que están empuñadas, a las que consideramos propiamente «lanzas» y las que están siendo arrojadas o clavadas en el enemigo, a las que llamamos «jabalinas» o arrojadizas. En ambos estilos predominan las últimas, tanto en escenas de caza como de enfrentamiento, es decir, son mayoritarias las escenas en las que aparecen en el momento en que son lanzadas o bien están clavadas sobre un enemigo.

En cuanto a los elementos defensivos, los cascos son más claramente identificables en el Estilo II que en el I, donde pueden confundirse con el propio pelo del personaje. En el Estilo I, un personaje representado en el vaso $\mathrm{n}^{\circ} 122$ lleva claramente un casco con una llamativa cimera. Este personaje aparece además con una panoplia completa. En el Estilo II, por el contrario, encontramos toda una tipología de cascos de la época, algunos con cimera, otros con penachos claramente dibujados (vaso ${ }^{\circ} 129$ ). Con esta composición se puede observar el conjunto más completo de todos los tipos de armas que pudieran utilizarse en este territorio, integrándolos en un baile de desfile, en el que las armas son un importante aderezo. Hay un caso que merece 
una mención aparte. Se encuentra en el vaso $n^{\circ} 16$ (Estilo II) donde un personaje aparece tocado con un casco tipo Montefortino, armamento defensivo excepcional en contextos ibéricos, por lo que podría estar representando a un guerrero no edetano, probablemente procedente del sureste peninsular (en El Cigarralejo, con 600 tumbas solo han aparecido dos casos; en Cabezo Lucero no ha aparecido ninguno, en Cabecico del Tesoro solo dos cascos). Quesada opina que puede tratarse de uso excepcional y símbolo de prestigio (Quesada, 1997:560), situado cronológicamente en la fase avanzada s. III-II a.C. de la panoplia (Quesada, 1997:619).

Por último, hemos de mencionar la combinación caetra/scutum, en ambos estilos: 12 caetrae y tres scuta en el Estilo I, y dos caetrae y 10 scuta en el Estilo II. El scutum, como ya adelantamos aparece en el mundo Mediterráneo a partir del s. V a.C.; según Quesada es posible que los ejércitos romanos y cartagineses los mostrasen en zona ibérica durante los s. IV - III a.C. Tanto el casco Montefortino como el scutum son variaciones en el armamento tradicional ibérico, producidas por alteraciones en las tácticas de lucha (Quesada, 2002-2003b). Los escudos redondos por el contrario (caetra) se utilizan en la península desde fases antiguas hasta época republicana. Ambos tipos de escudos pudieron por tanto coexistir en el TSM. De nuevo esta diferenciación en el uso de un arma entre los dos estilos, nos tentaría a sugerir una diferencia cronológica. Pero el uso de caetrae (Estilo I) y scuta (Estilo II) no es exclusivo. Por tanto debemos pensar en un uso más tradicional de la caetrae en el Estilo I, y más innovador (scuta) en el Estilo II.

Respecto a la panoplia que encontramos en los vasos, no vemos diferencias por estilos, aunque sí por escenas, como ya hemos comentado en los apartados anteriores. Ni tampoco existen diferencias notables entre la panoplia de los jinetes y la de los infantes. Esta panoplia, como también hemos apuntado, es la que Quesada denomina «panoplia avanzada o renovada» aunque el autor se basa precisamente en la iconografía del TSM.

En nuestro estudio de los diferentes yacimientos vecinos coincidimos con Quesada en establecer para la época del poblado del TSM una panoplia tipo compuesta por arma de astil (jabalina/lanza), falcata y escudo. Esto coincide en las escenas de enfrentamiento del Estilo I y Estilo II y las de parada del Estilo II, pero no con la panoplia de las escenas de caza del Estilo I, que mayoritariamente están representadas con armas de astil.

No podemos asegurar pues que, atendiendo a diferencias entre la panoplia de un estilo y otro, existiera una diferencia cronológica entre ambos. Dado que no existen dos vasos iguales y por tanto no podemos adscribir cada vaso a un taller diferente (Bonet, 1995: 440, Pérez Ballester en Aranegui et alii, 1997b: 153-154), ni una panoplia típica de un estilo y otro que pudiera mostrarnos claras diferencias cronológicas, los vasos de ambos estilos podrían corresponder a una misma época (e incluso a los mismos talleres). La variación entre la calidad de unos y de otros podría deberse a una diferenciación de la clase social que hiciera el encargo, a mayor categoría social, mejor realización del mismo (lo que supondría pagar un precio más elevado por él). Un dibujo más rápido y de menor precisión, con escenas cotidianas en el Estilo I, y una realización más cuidada, con una temática reflejo de la clientela que la solicita, la clase dirigente representada en sus momentos de ostentación, tales como paradas, desfiles o en momentos de enfrentamiento entre tribus o en algún acto heroico en el Estilo II. El predominio del scutum y la presencia del casco Montefortino en el mismo, reflejaría la contemporaneidad con los ejércitos cartaginés y romano, frente a una concepción más conservadora y menos «actual» en el Estilo I. La condición social del grupo humano que realizara el encargo influiría con seguridad en la calidad del diseño. 


\section{BIBLIOGRAFÍA}

Abad Casal, L. y Bendala Galán, M. (1989): “El arte ibérico”. Colección Historia del Arte, 10. Historia 16. Madrid.

Abad Casal, L. Sala Sellés, F. y Grau, I (eds.) (2005): La Contestania ibérica, treinta años después. Universidad de Alicante.

Aparicio Pérez, J. (2007): La necrópolis ibérica del Corral de Saus en el Complejo de Carmoxent (Moixent, Valencia). Diputación Provincial de Valencia, Sección de Estudios Arqueológicos. Valencia. 29-32.

Aranegui Gascó, C. et alii (1993): La nécropole ibérique de Cabezo Lucero (Guardamar del Segura, Alicante). Collection de la Casa de Velázquez, volumen $\mathrm{n}^{\circ} 41$. Madrid/Alicante.

Aranegui Gascó, C. (1996): "Signos de rango en la sociedad ibérica. Distintivos de carácter civil o religioso", REIb 2. 91-121.

Aranegui Gascó, C., Mata Parreño, C., Pérez Ballester, J. (1997a): Damas y Caballeros en la ciudad ibérica: las cerámicas de Llíria. Ed. Cátedra. Historia/Serie MenorMadrid.

Aranegui Gascó, C., Bonet Rosado, H., Martí, Mª A., Mata Parreño, C., Pérez Ballester, J. (1997b): “La cerámica con decoración figurada y vegetal del Tossal de Sant Miquel (Llíria, València): una nueva propuesta metodológica". Actas del Coloquio Internacional Iconografía Ibérica. Iconografía itálica. Propuestas de interpretación y lectura. Serie Varia, 3. Madrid.

Aranegui Gascó, C. (2005): "Arte ibérico en la Edetania". En: Lorenzo Abad Casal y Jordi A. Soler Díaz, (ed.). Actas del Congreso de Arte Ibérico en la España Mediterránea, Alicante, 24-27 de octubre de 2005. 167-184.

Arasa Gil, F. e Izquierdo Peraile, I. (1998): "Estela antropomorfa con inscripción ibérica del Mas de Barberán (Nogueruelas, Teruel)", AespA. 71-102.

Ballester Tormo, I. (1935): La labor del Servicio de Investigación Prehistórica y su Museo en el pasado año 1934. Diputación de Valencia. Valencia. 15-63.

Ballester, I., Fletcher, D., Plá, E., Jordá, F. y Alcácer, J. (1954): Corpus Vasorum Hispanorum. Cerámica del Cerro de San Miguel de Liria. Madrid.

Blázquez Martínez, J.M., García-Gelabert Pérez, M. P. (1990): "Estudio del armamento prerromano en la península ibérica a través de las fuentes y las representaciones plásticas”. Hispania Antiqua, 14. Madrid. 91-115.

Bernabeu Aubán, J. Bonet Rosado, H. y Mata Parreño, C. (1987): "Hipótesis sobre la organización del territorio edetano en época ibérica plena: el ejemplo del territorio de Edeta/Llíria", Iberos: actas de las I jornadas sobre el Mundo Ibérico: Jaén 1985. Jaén. 137-156.

Bonet Rosado, H. (1995): El Tossal de Sant Miquel de Llíria. La antigua Edeta y su territorio. Diputación de Valencia. Servicio de Investigación Prehistórica. Valencia.

Bonet Rosado, H. y Mata Parreño, C. (1982): "Nuevas aportaciones a la cronología final del Tossal de Sant Miquel (Llíria, Valencia)", Saguntum, 17. Valencia. 77-83.

Bonet Rosado, H. y Mata Parreño, C. (1997): "Lugares de culto edetanos. Propuesta de definición”. Espacios y lugares culturales en el mundo ibérico. Quaderns de Prehistòria i Arqueologia de Castelló, 18. Castellón. 115-146.

Bonet Rosado, H. y Mata Parreño, C. (1998): "La cerámica de importación durante los siglos III y principios del III a.C. en AA.CC., Les facies ceràmiques d'importació a la costa ibèrica, les Balears i les Pitiuses durant el segle III a.C i la primera meitat del segle II a.C.", Arqueomediterrània, 4. Barcelona. 49-72.

Bonet Rosado, H., Izquierdo Peraile, I. (2000): "Vajilla Ibérica y vasos singulares del área valenciana entre los siglos III y I a.C." Archivo Prehistoria Levantina, XXIV. Valencia.

Bonet Rosado, H. y Mata Parreño, C. (2002): El puntal dels Llops. Un fortín edetano. Diputación Provincial de Valencia. Servicio de Investigación Prehistórica. Valencia.

Coll Conesa, J. (2000): "Aspectos de tecnología de producción de la cerámica ibérica”, Saguntum, Extra-3, Valencia. 191-209.

Cortell, E., Juan, J. Llobregat, E. Reig, C., Sala, F., Segura, J. M. (1992): "La necrópolis ibérica de La Serreta: resumen de la campaña 1987", Estudios de Arqueología ibérica y romana. Homenaje a Enrique Pla Ballester. Trabajos Varios del Servicio de Investigación Prehistórica. Valencia. 89, 83-116. 
Cuadrado Díaz, E. (1968): Tumbas principescas de El Cigarralejo. MM 9, 148-186.

Cuadrado Díaz, E. (1979): Espuelas ibéricas. XV CNA, Lugo, 1977, 735-740.

Cuadrado Díaz, E. (1987): La necrópolis ibérica de El Cigarralejo (Mula, Murcia).

Biblioteca Praehistorica Hispana, XXIII. Madrid.

Cuadrado Díaz, E. (1989): La panoplia ibérica de El Cigarralejo (Mula, Murcia). Murcia Documentos. Serie Arqueológica. Murcia.

Díes Cusí, E., Bonet Rosado, H. (1996): "La Bastida de Les Alcuses. Trabajos de restauración e investigación". Revista de Arqueología, 185. Septiembre. 14-21.

Díes Cusí, E., Alvarez García, N. (1997): “Análisis del conjunto 5 de La Bastida de Les Alcuses (Mogente, Valencia): un edificio con posible funcionalidad cultural". Quaderns de Prehistòria y Arqueologia de Castelló, 18. Castellón. 147-170.

Díes Cusí, E., Bonet Rosado, H., Alvarez, N. Pérez Jordá, G. (1997): "La Bastida de Les Alcuses (Moixent): resultados de los trabajos de excavación y restauración, años 1990-1995", Archivo de Prehistoria Levantina, XXII. 215-296.

Domínguez Monedero, A. (2005): "Jinetes en Grecia y sus ecos en la cultura ibérica”. Gladius XXV, 207-236.

Farnié Lobensteiner, C. y Quesada Sanz, F. (2005): Espadas de hierro, grebas de bronce. Símbolos de poder e instrumentos de guerra a comienzos de la Edad del Hierro en la Península Ibérica. Monografías del Museo de Arte Ibérico de El Cigarralejo, 2. Murcia.

Fletcher Valls, D., Plá Ballester, E. Alcácer, J. (1965): La Bastida de Les Alcuses (Mogente, Valencia) Serie de Trabajos Varios, 24. Servicio de Investigación Prehistórica. Valencia.

Fuentes Albero, M. M. (2007): Vasos singulares de la Serreta (Alcoi, Cocentaina, Penàguila; Alacant). Fundación Municipal José M. Soler. Villena. Alacant.

García Cano, J.M. (1997): Las necrópolis ibéricas de Coimbra del Barranco Ancho (Jumilla, Murcia) I. Las excavaciones y estudio análitico de los materiales. Universidad de Murcia. Murcia.

Guerin, P. (2003): El castellet de Bernabé y el horizonte ibérico pleno edetano. Diputación de Valencia. Servicio de Investigación Prehistórica. Valencia.

González Navarrete, J.A. (1987): Escultura Ibérica de Cerrillo Blanco, Porcuna, Jaén. Diputación de Jaén. Jaén.

Grau Mira, I. (1996): "Estudio de las excavaciones antiguas de 1953 y 1956 en el poblado ibérico de La Serreta". Recerques del Museo d'Alcoi, 5. Alcoi, Alicante. 83-120.

Grau Mira, I., Reig Seguí, C. (2002-2003): "Sobre el uso de metales en la Contestania ibérica: las evidencias de La Serreta". Recerques del Museo d'Alcoi, 11/12. Alcoi, Alicante. 101-150.

Izquierdo Peralile, I. (en prensa): "Arqueología de la muerte y el estudio de la sociedad: una visión desde el género en la cultura ibérica”, en Sánchez Romero, M. (ed.), Arqueología y Género, Complutum. Madrid.

Izquierdo Peralile, I. (1995): "Un vaso inédito con excepcional decoración pintada de la necrópolis ibérica del Corral de Saus (Moixent, Valencia)". Saguntum, 29. Valencia. 93-104.

Izquierdo Peralile, I. (2000): Monumentos funerarios ibéricos: los pilares-estela. Serie de Trabajos Varios, 98. Servicio de Investigación Prehistórica. Valencia.

Izquierdo Peralile, I. y Pérez Ballester, J. (2005): "Grupos de edad y género en un nuevo vaso del Tossal de Sant Miquel de Llíria (València)". Saguntum, 37. Valencia. 86-103.

Kurtz, W. (1993): "Un posible tema heróico ibérico". Saguntum, 26. Valencia. 239-245.

Lamboglia, N. (1952): "Per una clasificazione prelimitare della ceramica campana". Atti del I Congreso Internazionale di Studi Liguri. Bordighera. 139-206.

Maestro Zaldíbar, E. (1977): "Notas sobre las representaciones de armamento en la cerámica ibérica de San Miguel de Liria”. Homenaje a Antonio Beltrán. Zaragoza. 581-588.

Maestro Zaldíbar, E. (1989): Cerámica Ibérica decorada con figura humana. Monografías arqueológicas, 31. Universidad de Zaragoza. Zaragoza.

Mata Parreño, C. (1993): Aproximación al estudio de las necrópolis ibéricas valencianas. Actes de l'homenatge a Miquel Tarradell. Estudis Universitaris Catalans. Barcelona. 429-448.

Molina García, J. y Nordstrom, S. (1976): Coimbra del Barranco Ancho (Jumilla-Murcia). Serie de Trabajos Varios, 52. Servicio de Investigación Prehistórica. Valencia.

Moltó Gisbert, S. y Reig Seguí, C. (1996): "La sepultura 53 de la necrópolis ibérica de La Serreta". Recerques del Museo d'Alcoi, 5. Alcoi. Alicante. 121-135. 
Morel, J.P. (1981): Ceràmique campanienne. Les formes, Befar, 244. École Française de Rome. París.

Morer de Llorens, J. y Rigo Jovells, A. (1999): Ferro i ferrers en el món ibèric. El poblat de les Guàrdies. (El Vendrell). Servei d'Arqueología de la Generalitat de Catalunya. Patronat Municipal de Serveis Culturals de l'Ajuntament del Vendrell.

Moret, P. y Quesada Sanz, F. (2002): "La guerra en el mundo ibérico y celtíbérico (siglos VI-II a.C.)". Collection de la Casa de Velázquez, volumen 78. Seminario celebrado en la Casa de Velázquez. Marzo 1996. Actas reunidas y presentadas por Pierre Moret y Fernando Quesada Sanz. Madrid.

Olcina Doménech, M. (1997): "Excavacions al poblat i necròpolis de La Serreta. Any 1997”. Recerques del Museo d'Alcoi, 6. Alcoi. Alicante.165-173.

Olcina Doménech, M. (2000): La Serreta. En Catàleg. Museu Arqueològic Municipal Camil Visedo Moltó. Alcoi. Alicante. 105-112.

Olcina Doménech, M. (2002): "Lucentum" en Valencia y las primeras ciudades romanas en Hispania. Valencia, 255-266.

Olcina Doménech, M., Grau Mira, I., Moltó Gisbert, S. (2000): El sector I de La Serreta: noves perspectives al voltant de l'ocupació de l'assentament, Recerques del Museo d'Alcoi, 9, Alcoi. Alicante 119-144.

Olcina Doménech, M., Grau Mira, I., F., Moltó Gisbert, S., Reig Seguí, C., I., Sala Sellés, F. y Segura Martí, J.M. (1998): "Nuevas aportaciones a la evolución de la ciudad ibérica: el ejemplo de La Serreta". Congreso Internacional Los Iberos. Príncipes de Occidente. Barcelona, 12-14 marzo 1998. Barcelona. 35-46.

Pérez Ballester, J., (1997): Decoraciones geométricas, vegetal y figurada: tres grupos de motivos interrelacionados en Aranegui, C. et alii (ed.): Damas y Caballeros en la ciudad ibérica. Madrid. $117-160$

Pérez Ballester, J. y Mata Parreño, C. (1998): "Los motivos vegetales en la cerámica del Tossal de Sant Miquel (Llíria, Valencia). Función y significado en los Estilos I y II". Actas del Congreso Internacional Los Iberos. Príncipes de Occidente. Barcelona. 232-243.

Pérez Ballester, J. y Borredà Mejías, R. (2004): La Carraposa (Rotglà i Corbera - Llanera de Ranes). Un lugar de culto ibérico en el Valle del Canyoles (La Costera, València). Deutsches Archäologisches Institut Abteilung Madrid. Sonderdruck aus Madrider Mitteilungen. 45.

Quesada Sanz, F. (1989): Armamento, Guerra y Sociedad en la necrópolis ibérica de "El Cabecico del Tesoro” (Murcia, España). B.A.R. Internacional Series 502, 2 vols. Oxford.

Quesada Sanz, F. (1992): Arma y símbolo. La falcata ibérica. Alicante. Instituto de Cultura Juan GilAlbert.

Quesada Sanz, F. (1997): El armamento ibérico. Estudio tipológico, geográfico, funcional, social y simbólico de las armas en la Cultura Ibérica (siglos VI-I a.C.) Vol. 1-2. Monographies Instrumentum, 3 . Èditions Monique Mergoil. Montagnac.

Quesada Sanz, F. (1998): “Aristócratas a caballo y la existencia de una verdadera caballería en la cultura ibérica; dos ámbitos conceptuales diferentes", en Aranegui, C. (ed.), Actas del Congreso Internacional Los Iberos, Príncipes de Occidente: Las estructuras del poder en la sociedad ibérica. Barcelona. 169-183.

Quesada Sanz, F. (2002): “Armas y arreos de caballo en la protohistoria peninsular. Problemas de la documentación y líneas de investigación prioritarias" en Moret, P. y Quesada, F. (eds.): La guerra en el mundo ibérico y celtibérico (ss. VI-II a.de C.). Collection de la Casa de Velázquez, volumen, 78. Madrid. 1-34.

Quesada Sanz, F. (2002-2003a): "Mirando el mundo desde lo alto: espuelas y otros elementos asociados al caballo en el poblado de La Serreta d'Alcoi"._Recerques del Museo d'Alcoi, 11/12. 85-100.

Quesada Sanz, F. (2002-2003b): "Innovaciones de raíz helenística en el armamento y tácticas de los pueblos ibéricos desde el siglo III a.C." CUPAUAM, 28-29. 69-94.

Quesada Sanz, F. (2005a): "El gobierno del caballo montado en la Antigüedad clásica con especial referencia al caso de Iberia. Bocados, espuelas y la cuestión de la silla de montar, estribos y herraduras". Gladius XXV, 97-150.

Quesada Sanz, F. (2005b): El guerrero ibérico a través de El Cigarralejo. Museo de Arte Ibérico El Cigarralejo. Murcia. 111-134

Quesada Sanz, F. (2006): "Not so different: individual fighting techniques and small unit tactics of Roman and Iberian armies within the Framework or warfare in the Hellenistic Age. L'Hellénisation 
en Mediterranée Occidentale au temps des guerres puniques". Actes du Colloque International de Toulouse, 31 mars-2 avril 2005. Pallas 70. 245-263.

Quesada Sanz, F. (2010): "Las armas en los poblados ibéricos: teoría, método y resultados". Gladius XXX, 17-41.

Quesada Sanz, F. y Zamora Merchán, M. (eds.) (2003): El caballo en la Antigua Iberia. Estudios sobre los équidos en la Edad del Hierro. Biblioteca Archaeologica Hispana 19. Real Academia de la Historia. Madrid.

Reig Seguí, C. (2000): "El armamento de la necrópolis ibérica de La Serreta”, Gladius, XX. Madrid. 75-117.

Rosser, P. y Fuentes, C. (2007): Tossal de Les Basses. Seis mil años de historia de Alicante. Patronato Municipal de Cultura. Ayuntamiento de Alicante.

Rovira Hortalá, C. (2000): Los talleres de herrero en el mundo ibérico: aspectos técnicos y sociales. III Reunió sobre Economia del Món Ibèric. Saguntum (PLAV) Extra-3. Valencia. 265-270.

Rubio Gomis, F. (1986): La necrópolis ibérica de La Albufereta de Alicante. Academia de Cultura Valenciana. Sección de Prehistoria y Arqueología. Valencia.

Tiemblo Magro, A. (1999): "Iconografía Del rostro frontal en la cerámica ibérica". Complutum, 10. 175-194.

Tortosa Rocamora, T. (2006): Los estilos y grupos pictóricos de la cerámica ibérica figurada de La Contestania. Instituto de Arqueología de Mérida. Mérida.

Sandars, H. (1913): "The weapons of the iberians". Archeologia, LXXV. 44-45.

Valenciano Prieto, M. (2000): El Llano de la Consolación (Montealegre del Castillo, Albacete). Revisión crítica de una necrópolis ibérica del sureste de la Meseta. Diputación de Albacete. Albacete.

Verdú Parra, E. (2005): Francisco Figueras Pacheco y las excavaciones en la necrópolis ibérica de La Albufereta de Alicante (1934-1936). Museo Arqueológico de Alicante. Alicante.

Recibido: 29/04/2011

Aceptado: 21/06/2013 